\title{
Multifunctional gold nanorods and docetaxel- encapsulated liposomes for combined thermo- and chemotherapy
}

This article was published in the following Dove Press journal:

International Journal of Nanomedicine

25 October 2017

Number of times this article has been viewed

\author{
Haiying Hua ${ }^{1, *}$ \\ Nan Zhang ${ }^{2,3, *}$ \\ Dan Liu' \\ Lili Song' \\ Tuanbing Liu',3 \\ Shasha $\mathrm{Li}^{2,3}$ \\ Yongxing Zhao 2,3 \\ 'Academy of Medical and \\ Pharmaceutical Sciences, ${ }^{2}$ Department \\ of Pharmaceutics, School of \\ Pharmaceutical Sciences, Zhengzhou \\ University, ${ }^{3}$ Key Laboratory of \\ Targeting Therapy and Diagnosis \\ for Critical Diseases, Zhengzhou, \\ Henan, China \\ *These authors contributed equally \\ to this work
}

Correspondence: Yongxing Zhao

Department of Pharmaceutics, School

of Pharmaceutical Sciences, Zhengzhou

University, No 100 KeXue Avenue,

Room A3 I5, Zhengzhou 45000I,

Henan, China

Tel +86 37I 67739165

Fax +86 37I 67739546

Email zhaoyx@zzu.edu.cn

\begin{abstract}
Personalized and precise nanomedicines are highly demanded for today's medical needs. Liposomes are ideal candidates for the construction of multifunctional drug delivery systems. In this study, a liposome was used to improve the clinical issues of docetaxel (Doc), a potent antimitotic chemotherapy for prostate cancer (PC). RLT, a low-density lipoprotein receptor (LDLR)-binding peptide, and PEG were conjugated to the liposomes, and gold nanorods (GNRs) were also incorporated into the liposomes. The GNRs/Doc-liposome-RLT (GNRs/ DocL-R) was tested in PC-3 cells and in PC-3 tumor-bearing nude mice. Results showed that GNRs/DocL-R possessed a diameter approximately $163.15 \pm 1.83 \mathrm{~nm}$ and a zeta potential approximately $-32.8 \pm 2.16 \mathrm{mV}$. GNRs/DocL-R showed enhanced intracellular entrance, increased accumulation in the implanted tumor region, and the highest tumor inhibition in vitro and in vivo. Therefore, the multifunctional GNRs/DocL-R was a potential cancer treatment via combined chemo- and thermotherapy.
\end{abstract}

Keywords: gold nanorods, docetaxel, liposomes, prostate cancer, LDL receptor targeting

\section{Introduction}

Cancers are still unmet medical issues with increasing incidence and high mortality. Cancer cells are difficult to control because of their fast proliferation, invasive migration, poor drug permeability, adaptive drug resistance, and multiple self-protective mechanisms. A combined therapy of two or more anticancer agents is an ideal strategy for enhanced efficacy. The combined therapy should possess minimum toxicity to healthy tissues and organs. Gold nanorods (GNRs) have been explored as anticancer agents $^{1-3}$ for photothermal therapy (PTT). GNRs possess a transverse absorption at the wavelength of $520 \mathrm{~nm}$ and a longitudinal peak at the near-infrared (NIR) region. ${ }^{4,5}$ GNRs have the maximum absorption and the highest heating efficiency around $800 \mathrm{~nm} .^{6}$ NIR light has deep tissue penetration and causes minimum damage to normal tissues. ${ }^{7}$ By applying NIR light, absorbed light by GNRs was converted into local heating ${ }^{8}$ that would cause cell injury/death via cell necrosis and/or apoptosis. ${ }^{2,9}$ Docetaxel (Doc) is a potent and broad-spectrum anticancer drug that acts on the synthesis, migration, and division of microtubules to inhibit the growth of cancer cells. ${ }^{10}$ However, GNRs possessed poor stability in biological environment and reduced cellular uptake. ${ }^{11}$ Doc is a lipophilic compound that has poor specificity and high toxicity in vivo. ${ }^{10}$ These disadvantages limit the applications and anticancer efficacy of GNRs and Doc.

Liposomes have been the earliest and most well-developed drug delivery systems since 1965 . Over the past 5 decades, many efforts have been performed to prolong 
the in vivo circulation of liposomes, control the release rate of drugs from liposomes, and improve the tumor targeting of liposomes; therefore, some liposomal formulations have entered the market. ${ }^{12}$ The natural merits of liposomes make them to be ideal candidates for the construction of multifunctional drug delivery systems and advantageous tools to apply combined therapies.

Low-density lipoprotein receptors (LDLRs) were overexpressed on the membrane of cancer cells to take extra essential fatty acids for cell proliferation. ${ }^{13}$ Hayavi and Halbert $^{14}$ first synthesized an LDLR-binding peptide RLT (CEKLKEAFRLTRKRGLKLA, underlined sequence represented the binding region to LDLR) that preserved the binding sequence of native low-density lipoprotein (LDL). Lysine (Lys) and Arginine (Arg) are amino acids with positive charges and were added to RLT to assist endo-lysosome escape. Later studies proved that RLT could bind to LDLR and be taken up via LDLR-mediated endocytosis. RLT could also facilitate the delivery of paclitaxel to glioblastoma multiforme cells and improve the efficacy of paclitaxel. ${ }^{15,16}$ RLT-modified DNA nanocomplexes showed enhanced intracellular delivery of doxorubicin (Dox) and higher tumor cell inhibition. ${ }^{17}$ In addition, in vivo studies confirmed that RLT increased the tumor accumulation of submicron emulsion and GNRs in mice. ${ }^{3,18}$ In this study, liposomes are used to improve the application of GNRs and Doc by encapsulating lipophilic Doc into the bilayer of liposomes and loading GNRs into the hydrophilic core of liposomes. Polyethylenes glycol (PEG) and RLT were conjugated to the liposomes to increase the stability and tumor targeting of liposomes. The PEG- and RLT-modified liposomes, and GNRs and Doc-loaded liposomes (GNRs/Doc-liposome-RLT, GNRs/DocL-R), were then characterized and investigated for in vitro and in vivo antitumor efficacy and safety.

\section{Materials and methods Materials}

Sodium borohydride $\left(\mathrm{NaBH}_{4}\right)$, chloroauric acid trihydrate $\left(\mathrm{HAuCl}_{4} \cdot 3 \mathrm{H}_{2} \mathrm{O}\right)$, cetyltrimethyl-ammonium bromide (CTAB), silver nitrate $\left(\mathrm{AgNO}_{3}\right)$, sodium sulfate $\left(\mathrm{Na}_{2} \mathrm{SO}_{4}\right)$, and L-ascorbic acid (AA) were purchased from Alfa chemicals (Berkshire, UK). Ultrapure Milli-Q water (18 M $\Omega$ cm; Millipore-Q; EMD Millipore, Billerica, MA, USA) was used for all solution preparations. Sangon Biotech (Shanghai, China) provided cholesterol (chol). Aladdin (Shanghai, China) supplied soy phosphatidylcholine (SPC) and hydrogenated SPC (HSPC). 1,2-Distearoyl-sn-glycero-3-phosphoethanolamineconjugated polyethylene glycol (DSPE-PEG (2000)-Mal) was obtained from Nanocs (NY, USA). RLT(-SH) and fluorescein isothiocyanate (FITC)-labeled RLT(-SH) were synthesized by AC Scientific (Xi'an, China). Doc and Dox were purchased from Hisun (Zhejiang, China). HyClone (Logan, UT, USA) supplied penicillin-streptomycin solution $(100 \times)$ and $0.25 \%$ trypsin. MTT kit was purchased from Sigma-Aldrich Co. (St Louis, MO, USA). Solarbio ${ }^{\circledR}$ Life Sciences (Beijing, China) provided dimethyl sulfoxide (DMSO), RPMI-1640 cell culture medium, apoptosis assay kit, cell cycle kit, and reactive oxygen species (ROS) probe (dichloro-dihydro-fluorescein diacetate [DCFH-DA]). 1,1-Dioctadecyl-3,3,3,3-tetramethylindotricarbocyanine iodide (DiR iodide) was purchased from AAT Bioquest (Sunnyvale, CA, USA). Prostate cancer cell line (PC-3) was obtained from Chinese Academy of Science Cell Bank for Type Culture Collection (Shanghai, China).

\section{Preparation and characterization of GNRs/DocL-R}

GNRs were synthesized using a modified seed-mediated growth method in aqueous solution as described previously (Supplementary materials). ${ }^{19-21}$ GNRs/DocL-R was prepared by using lipid-film hydration method. ${ }^{22}$ Briefly, chol $(10 \mathrm{mg}$, $25.9 \mathrm{nM}), \mathrm{SPC}(150 \mathrm{mg}, 193.4 \mathrm{nM}), \mathrm{HSPC}$ (5 mg, $6.4 \mathrm{nM})$, Doc (5.5 mg, 6.8 nM), and DSPE-PEG (2000)-Mal (2.5 mg, 0.88 $\mathrm{nM}$ ) were dissolved in chloroform using bath sonication. Chloroform was then removed by rota-evaporation, and the lipid solution was dried to a thin and transparent film at the bottom of flask. GNR solution ( $0.4 \mathrm{nM}, 4 \mathrm{~mL})$ was then added to the flask to hydrate the film. The flask was sonicated in ice bath for 40 times $(200 \mathrm{~W}$ ) (every sonication lasted for $3 \mathrm{~s}$; every sonication contained two $3 \mathrm{~s}$ sonication), and the obtained solution was centrifuged at $8,000 \mathrm{rpm}$ for $10 \mathrm{~min}$. Supernatant was obtained and mixed with RLT $(1.2 \mu \mathrm{g}, 0.44 \mathrm{nM})$ solution $(24 \mu \mathrm{L})$. The mixture was vortexed for $1 \mathrm{~min}$ and shaken for $12 \mathrm{~h}$ at room temperature to obtain GNRs/DocL-R.

Size and zeta potential of GNRs/DocL-R were analyzed by Zetasizer Nano ZS90. The morphology of GNRs/DocL-R was observed under transmission electron microscopy (TEM; TecnaiG20; FEI, Hillsboro, OR, USA). Briefly, fresh samples were diluted in Millipore water and mixed well. Before visualization, the fresh samples were placed on copper grids with film and settled for $1 \mathrm{~min}$. Excess liquid was absorbed by paper, and the samples were air dried before TEM examination.

\section{Loading and release of Doc and thermal responses of GNRs/DocL-R}

Loading efficiency (LE) and loading capacity (LC) were analyzed by high-performance liquid chromatography 
(HPLC; Agilent 1100 [Beijing, China]; flow rate: $1.0 \mathrm{~mL} /$ min; mobile phase: acetonitrile/water 53/47; column: Diamonsil ${ }^{\mathrm{TM}} \mathrm{C} 18,4.6 \times 200 \mathrm{~mm}, 5 \mu \mathrm{m}$; detection wavelength: $230 \mathrm{~nm}$, and temperature: $25^{\circ} \mathrm{C}$ ). The in vitro release of Doc was carried out using a dialysis unit (molecular weight cutoff [MWCO] 20,000 Da; Thermo Fisher Scientific, Waltham, MA, USA) at $37^{\circ} \mathrm{C}$. Briefly, $1 \mathrm{~mL}$ of GNRs/DocL-R (concentration of GNRs $0.4 \mathrm{nM}$ ) was sealed to a dialysis unit. The dialysis unit was submerged into $50 \mathrm{~mL}$ PBS that contained $0.5 \%(\mathrm{w} / \mathrm{w})$ Tween $80(\mathrm{pH} 7.4$ or $\mathrm{pH} 5.0)$. The dialysis unit with GNRs/DocL-R (concentration of GNRs $0.4 \mathrm{nM})+$ laser was exposed to laser radiation $(808 \mathrm{~nm})$ for $10 \mathrm{~min}$. At set time points $(0.5,1,2,4,8,12,24,48,72,96$, and $120 \mathrm{~h}), 1 \mathrm{~mL}$ of release media was withdrawn and $1 \mathrm{~mL}$ of fresh $0.5 \%(\mathrm{w} / \mathrm{w})$ Tween 80 PBS solution was refilled. The obtained release samples were centrifuged at 10,000 rpm for $10 \mathrm{~min}$. Supernatants were analyzed by HPLC to calculate the cumulative release (\%) of Doc.

To test thermal response, GNRs/DocL-R was exposed to laser radiation at $808 \mathrm{~nm}$ for $10 \mathrm{~min}$. Temperature increase was recorded at set time points. Curves of thermal response to laser radiation were plotted.

\section{In vitro cell inhibition}

PC-3 cells were in an exponential growth phase and cultured in RPMI-1640 medium supplemented with $10 \%(\mathrm{v} / \mathrm{v})$ fetal bovine serum (FBS; $5 \% \mathrm{CO}_{2}, 37^{\circ} \mathrm{C}$ ) unless otherwise specified. Cells were incubated for $24 \mathrm{~h}$ prior to the experiment. Cell inhibition was evaluated by the standard MTT assay. Briefly, a serial dilutions of GNRs, GNRs + laser, Doc, GNRs/DocL, GNRs/DocL + laser, GNRs/DocL-R, and GNRs/DocL-R + laser (corresponding Doc concentrations $1,10,20,40,60,80,100$, and $120 \mu \mathrm{g} / \mathrm{mL}$ ) were added to cells in 96-well plates (cell density $1 \times 10^{5}$ cells/well) and incubated for $12,24,48$, and $72 \mathrm{~h}$ to determine cell viability. Groups with laser radiation $(808 \mathrm{~nm})$ were exposed to laser for $5 \mathrm{~min}$ after $4 \mathrm{~h}$ of treatment. Standard MTT assay was conducted after these treatments. The absorbance of samples was measured at $490 \mathrm{~nm}$ using a Synergy $\mathrm{H} 1$ plate reader (BioTek, Vinooski, VT, USA). The cell inhibition rate was calculated, and the time- and concentration-dependent cell inhibition curves were plotted.

\section{Intracellular uptake}

PC-3 cells were seeded at a density of $2 \times 10^{5}$ cells/well in six-well plates over glass cover slips. Dox was selected as the fluorescent probe, and RLT was labeled with green FITC. Cells were incubated with Dox $(1 \mu \mathrm{g} / \mathrm{mL})$, GNRs/
DoxL (Dox concentration of $1 \mu \mathrm{g} / \mathrm{mL}$ ), and GNRs/DoxL-R (Dox concentration of $1 \mu \mathrm{g} / \mathrm{mL}$ ) for 1,2 , or $4 \mathrm{~h}$ at $37^{\circ} \mathrm{C}$ in the dark. Subsequently, the culture medium was removed, and the cells were washed thrice with PBS (pH 7.4). About $70 \%$ cold ethanol was used to fix the cell samples for $15 \mathrm{~min}$ at room temperature and gently washed twice with PBS. The prepared samples were observed using confocal laser scanning microscopy (Olympus FV1000; Olympus Corporation, Tokyo, Japan). Intracellular uptake was quantified using flow cytometry. After incubation with treatments for 1,2 , or $4 \mathrm{~h}$ at $37^{\circ} \mathrm{C}$, trypsin was added to PC-3 cells, and the detached cells were collected into centrifuge tubes. The cells were washed with PBS thrice. The purified cell samples were collected into fluorescence activated cell sorting tubes to quantify fluorescence signals.

\section{Flow cytometric analysis}

\section{Cell apoptosis analysis}

Doc $(50 \mu \mathrm{g} / \mathrm{mL})$, GNRs + laser, and GNRs/DocL-R (+laser) (Doc concentration of $50 \mu \mathrm{g} / \mathrm{mL}$ ) were added to PC-3 cells (cell density of $2.5 \times 10^{5}$ cells/well) in six-well plates and incubated with the cells for $24 \mathrm{~h}$. Subsequently, the cells were washed with PBS three times and incubated with trypsin (no EDTA). The obtained cell suspensions were centrifuged at $1,000 \mathrm{rpm}$ for $10 \mathrm{~min}$, and the cell pellets were suspended with $1 \mathrm{~mL}$ of cold PBS. The cells were washed twice using centrifugation. The purified cell pellets were suspended in $200 \mu \mathrm{L}$ of binding buffer and then mixed with Annexin V-FITC $(10 \mu \mathrm{L})$ and propidium iodide (PI; $10 \mu \mathrm{L}$ ). The cell solutions were incubated for $15 \mathrm{~min}$ in the dark. The additional $300 \mu \mathrm{L}$ of binding buffer was gently added. The prepared samples were tested immediately using flow cytometry.

\section{Cell cycle analysis}

Doc $(50 \mu \mathrm{g} / \mathrm{mL})$, GNRs/DocL-R (Doc concentration of $50 \mu \mathrm{g} / \mathrm{mL}$ ), and GNRs/DocL-R (+laser) (Doc concentration of $50 \mu \mathrm{g} / \mathrm{mL}$ ) were added to PC-3 cells (cell density of $2.5 \times 10^{5}$ cells/well) in six-well plates and incubated with the cells for $24 \mathrm{~h}$. Subsequently, the cells were washed with PBS three times and incubated with trypsin (no EDTA). The cell suspensions were centrifuged at $1,000 \mathrm{rpm}$ for $10 \mathrm{~min}$. The cell pellets were suspended with $500 \mu \mathrm{L}$ of cold ethanol and kept at $4^{\circ} \mathrm{C}$ overnight in the dark. The cell samples were washed with PBS before staining. RNase A $(100 \mu \mathrm{L})$ was used to suspend the cells, and the cell suspensions were incubated for $30 \mathrm{~min}$ at $37^{\circ} \mathrm{C}$. About $400 \mu \mathrm{L}$ of PI was then added, and the cell samples were incubated at $4^{\circ} \mathrm{C}$ for $30 \mathrm{~min}$ 
in the dark. The prepared samples were examined using a flow cytometer and analyzed by FlowJo software.

\section{ROS analysis}

Doc (50 $\mu \mathrm{g} / \mathrm{mL}$ ), GNRs, GNRs + laser, GNRs/DocL-R (Doc concentration of $50 \mu \mathrm{g} / \mathrm{mL}$ ), and GNRs/DocL-R (+laser) (Doc concentration of $50 \mu \mathrm{g} / \mathrm{mL}$ ) were added to PC-3 cells (cell density of $2.5 \times 10^{5}$ cells/well) in six-well plates and incubated with the cells for $24 \mathrm{~h}$. Subsequently, cells were subsequently washed with PBS three times and incubated with trypsin (no EDTA). The cell suspensions were centrifuged at 1,000 rpm for $10 \mathrm{~min}$. ROS probe (DCFH-DA) was diluted with culture medium (no serum) to $10 \mu \mathrm{M}$, and $1 \mathrm{~mL}$ of DCFH-DA solution was mixed with cells. The cell suspensions were incubated for $20 \mathrm{~min}$ at $37^{\circ} \mathrm{C}$ with gentle mixing every $5 \mathrm{~min}$. Next, the cells were washed with culture medium (no serum) three times and suspended with $500 \mu \mathrm{L}$ of culture medium (no serum) for ROS quantification using flow cytometry.

\section{In vivo studies}

BALB/c-nu male nude mice were purchased from the HuNan Experimental Animal Center of the Chinese Academy of Science. Animal care and experiments were performed with the approval of the animal ethical committee of Zhengzhou University (Zhengzhou, China), according to the requirements of the National Act on the Use of Experimental Animals (China). All animals were kept in a favorable environment and were acclimated at $25^{\circ} \mathrm{C}$ and $55 \%$ of humidity under natural light/dark conditions, with free access to a rodent diet and water. The experimental animals were acclimated for 1 week before the beginning of the study. The in vivo studies were conducted on 5-week-old nude mice with body weight around 18-20 g. PC-3 cells were collected from cell culture by trypsinization and subcutaneously implanted $\left(1 \times 10^{7}\right.$ cells in $200 \mu \mathrm{L}$ of culture medium) in the upper-right flank of anesthetized nude mice. When PC-3 xenograft volume reached $100 \mathrm{~mm}^{3}$, the prostate cancer (PC) models were established successfully, and the nude mice were randomly divided into experimental groups. All procedures followed the guidelines of the institutional animal ethical committee of Zhengzhou University (Zhengzhou, China).

\section{In vivo biodistribution}

DiR iodide emits weak fluorescence in water but strong fluorescence in cell membrane or lipophilic biomacromolecules. The dark red fluorescence from DiR iodide can efficiently penetrate cells and tissues, which makes DiR iodide an ideal fluorescent dye for in vivo imaging. GNRs/DiR liposomes and GNRs/DiR-RLT liposomes were prepared as described in Supplementary materials. The PC-3 xenograftimplanted nude mice were divided into three groups. DiR solution (100 $\mu \mathrm{g} / \mathrm{mL}$; dose $1 \mathrm{mg}$ DiR/kg mice), GNRs/DiR liposomes (dose $1 \mathrm{mg}$ DiR/kg mice), and GNRs/DiR-RLT liposomes (dose $1 \mathrm{mg} \mathrm{DiR} / \mathrm{kg}$ mice) were given to the nude mice via tail vein injection. At set time points $(1,2,4,8,12$, $24,48)$, the nude mice were anesthetized, and the dynamic fluorescent distribution in the nude mice was recorded by In Vivo FX PRO (excitation wavelength 748 nm, emission wavelength $780 \mathrm{~nm}, \mathrm{X}$-ray exposure time $30 \mathrm{~s}$ ) (Bruker; Billerica, MA, USA).

\section{Antitumor efficacy}

The nude mice were randomly assigned into six treatment groups: saline, Doc solution (concentration $10 \mathrm{mg} / \mathrm{kg}$ mice/3 days), GNRs/DocL (concentration of Doc: $10 \mathrm{mg} / \mathrm{kg}$ mice/3 days), GNRs/DocL (+laser) (concentration of Doc: $10 \mathrm{mg} / \mathrm{kg}$ mice/3 days), GNRs/DocL-R (concentration of Doc $10 \mathrm{mg} / \mathrm{kg}$ mice/3 days), and GNRs/DocL-R (+laser) (concentration of Doc $10 \mathrm{mg} / \mathrm{kg}$ mice/3 days). The treatments were given to nude mice via tail vein injection at set days (day 1 , day 4 , day 7 , day 10 , day 13 ). The PC xenograft size and body weights of the mice were measured the day before injections. At day 15, the mice were sacrificed, and the PC xenografts were excised and weighed after euthanizing the mice.

\section{Statistical analysis}

All experiments in this study were conducted at least in triplicate. Statistical analyses were performed using SPSS 18.0 (SPSS Inc., Chicago, IL, USA), Origin 8.0, and GraphPad Prism 6 software (GraphPad Software, Inc., La Jolla, CA, USA). Quantified data were presented as mean \pm SD. Student's $t$-test was applied to compare between two groups, and one-way analysis of variance (ANOVA) was performed to compare three or more groups ( $p$-values $<0.05$ indicated statistical significance).

\section{Results}

\section{Preparation and characterization of GNRs/DocL-R}

Doc is a potent antimitotic drug for PC, but the application of Doc is limited by the side effects and high tendency of cellular drug resistance of Doc. A multifunctional liposome that contained GNRs and Doc was designed and constructed in this study to improve Doc for PC treatment. The structure and compositions of the liposome are illustrated in Figure 1A. 

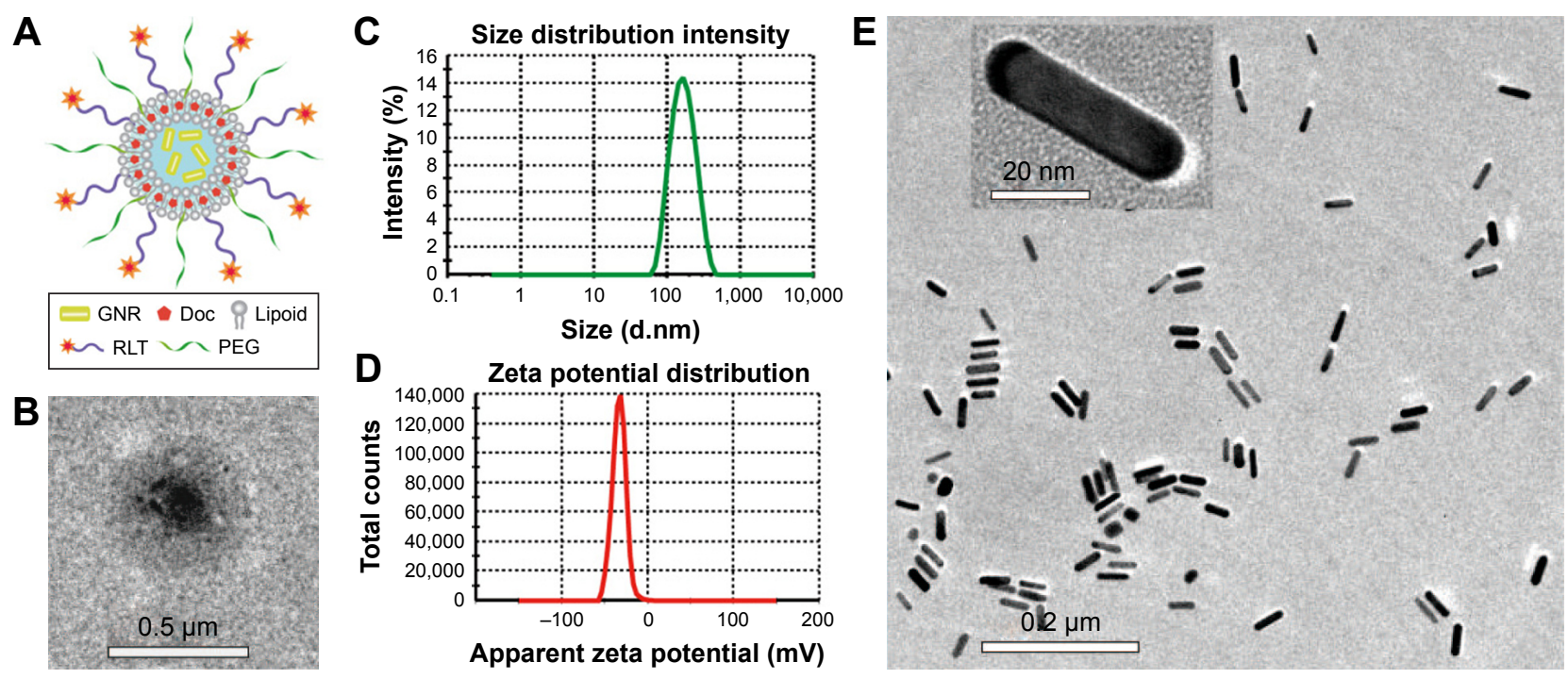

Figure I Characterization of GNRs and GNRs/DocL-R.

Notes: (A) The compositions and structure of GNRs/DocL-R. (B) A TEM image of GNRs/DocL-R. (C) Particle size distribution of GNRs/DocL-Rby dynamic light scattering. (D) Zeta potential distribution of GNRs/DocL-R by Zetasizer. (E) A TEM image of GNRs.

Abbreviations: Doc, docetaxel; GNRs, gold nanorods; GNRs/DocL-R, GNRs/Doc-liposome-RLT; TEM, transmission electron microscopy.

The liposomes were composed of GNRs, Doc, lipoid (chol, SPC, and HSPC), PEG, and RLT. The TEM image showed a round shape of the multifunctional liposomes and a central location of GNRs (Figure 1B). Diameter and zeta potential of the liposomes were around $163.2 \mathrm{~nm}$ and $-32.8 \mathrm{mV}$, respectively (Figures 1B, C and D). The TEM images of GNRs are shown in Figure 1E. The size of GNRs was $40 \mathrm{~nm}$ (length) $\times 10 \mathrm{~nm}$ (diameter). At aspect ratio (L:D) 4, GNRs have strong absorbance at a wavelength around $810 \mathrm{~nm}$. Three different GNR concentrations were used to prepare liposomes. There were no significant differences between the size and polydispersity index (PDI) of the GNRs/DocL-R prepared using GNRs with different concentrations (Figure 2A). However, negative charge of the liposomes reduced with increased GNR concentration (Figure 2B). At a higher concentration of GNRs $(0.635 \mathrm{nM})$, the aggregation of GNRs was observed after a few days, indicating a low stability (Table S1). Figure 3A shows a lower temperature increase after laser radiation using low GNR concentration. Therefore, to ensure the heating efficiency and stability of GNRs in vitro and in vivo, $0.4 \mathrm{nM}$ of GNRs was selected. Lipoid contained chol, SPC, and HSPC. HSPC was reduced from SPC by the addition of hydrogen and has significantly increased stability and phase transition temperature compared to SPC. The addition of HSPC can increase the stability of the liposomes. Varied ratios between SPC and HSPC were used to prepare the liposomes. Results showed that at SPC:HSPC (1:30; Table S2), optimized liposomes were obtained. Chol can regulate the mobility of the double-layer membrane of lipoid and reduce the permeability of the liposomes. The addition of Chol could increase the stability and reduce the drug leakage of the liposomes. At the ratio of (HSPC + SPC):Chol (8:1), the liposomes showed a high stability and a proper particle size (Table S3). RLT was conjugated to the liposomes via DSPE-PEG (2000)-Mal. DSPE-PEG (2000)-Mal was added during the preparation of liposomes. Partial DSPE-PEG (2000)-Mal might distribute into the inner layer of the double-layer membrane of the liposomes and could not react with RLT. HPLC was used to quantify conjugated RLT (Supplementary materials). Results showed that a higher DSPE-PEG (2000)-Mal:RLT ratio (3:1) resulted in a higher conjugation percentage of RLT (\%) to DSPE-PEG (2000)-Mal ( $90 \%$; Table S4, Figure 2C). Because of the low concentration of DSPE-PEG (2000)-Mal to maintain a stable liposome system, higher DSPE-PEG (2000)-Mal:RLT ratio (3:1) led to a lower RLT concentration $(0.1125 \%)$. Other studies reported the trend that nanoparticles with a higher percentage of targeting agents showed more internalization by the targeted cells. ${ }^{23,24}$ A low RLT modification rate may reduce the targeting ability of the liposomes. Therefore, molar ratio of DSPE-PEG (2000)-Mal:RLT (2:1) was selected in this study. In sum, the ratio of SPC:HSPC:Chol (1:30:3.75) was used to prepare a stable liposome. Molar modification rates of DSPE-PEG (2000)-Mal and RLT to the liposomes were $0.375 \%$ and $0.133 \%$, respectively, and $200 \mathrm{~W}$ and $240 \mathrm{~s}$ were selected as the optimized power and time of sonication, respectively (Table S5, Figure 2D). 
A
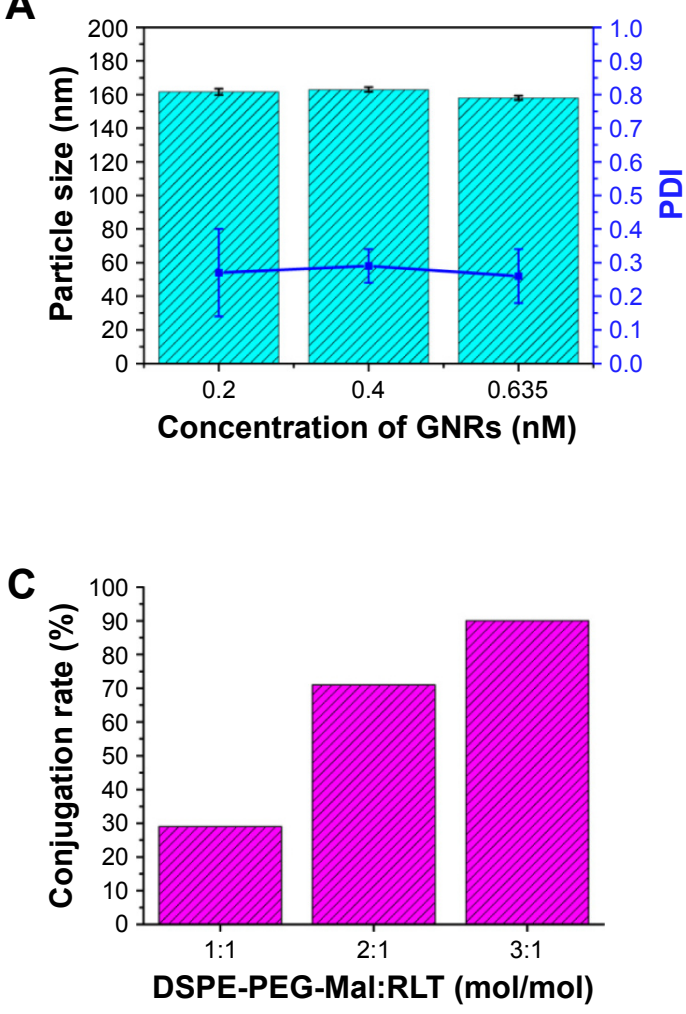

B
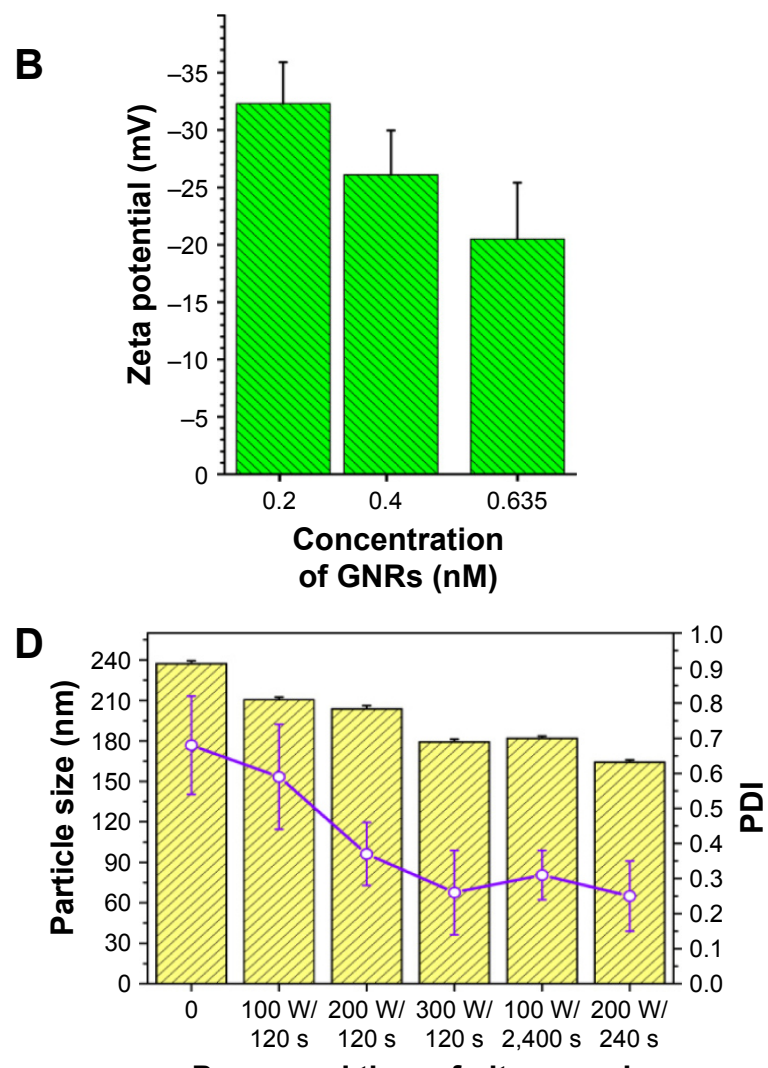

Power and time of ultrasound

Figure 2 The optimization of compositions and preparation of GNRs/DocL-R.

Notes: (A) Influence of GNR concentration on the size and PDI of GNRs/DocL-R. (B) Influence of GNR concentration on the zeta potential of GNRs/DocL-R. (C) Influence of DSPE-PEG-Mal:RLT molar ratio on the conjugation rate of RLT. (D) Influence of power and time of ultrasound on the size and PDI of GNRs/DocL-R.

Abbreviations: Doc, docetaxel; GNRs, gold nanorods; GNRs/DocL-R, GNRs/Doc-liposome-RLT; PDI, polydispersity index.

\section{Release of Doc and thermal responses of GNRs/DocL-R}

The LE and LC of Doc were $98.45 \% \pm 0.37 \%$ and $1.41 \pm 0.11 \mathrm{mg} / \mathrm{mL}$, respectively. About $0.5 \%$ (w/w) Tween 80 was added to PBS to increase the solubility of Doc in PBS. The results showed that laser radiation and low $\mathrm{pH}$ accelerated Doc release (Figure 3B and C). Temperature increase caused by laser radiation possibly reduced the stability of liposomes and resulted in Doc release. Figure 3C shows the relationship between the concentration of GNRs and laser radiation-induced temperature increase. The results indicated that a higher GNR concentration could produce a higher temperature for thermal therapy.

\section{PC-3 cell inhibition and intracellular uptake by PC-3 cells}

Concentration- and time-dependent PC-3 cell inhibition was examined. All the listed treatments showed a higher cell inhibition rate than free Doc (Figure 4A). The addition of GNRs to the liposomes (GNRs/DocL) did not cause more cell inhibition, whereas laser radiation induced a higher cell inhibition rate. The conjugation of RLT also enhanced PC-3 cell inhibition. At Doc of $80 \mu \mathrm{g} / \mathrm{mL}$, timedependent cell inhibition (Figures $4 \mathrm{~B}$ and S1) showed a similar trend with concentration-dependent cell inhibition. Free Doc caused a low cell inhibition rate, whereas Docloaded liposomes caused significant cell inhibition. The multifunctional liposomes (GNRs/DocL-R with(out) laser radiation) result in the cell inhibition rates to around $100 \%$. With $24 \mathrm{~h}$ incubation, the cell inhibition rate caused by Doc plus GNRs + laser was approximately equal to that caused by GNRs/DocL-R + laser (additive effect); however, the cell inhibition rate using GNRs/DocL-R + laser treatment was higher than that using Doc plus GNRs + laser (synergistic effect) with longer incubation ( $48 \mathrm{~h}$ and $72 \mathrm{~h}$ ), indicating a shift from the additive effect of Doc and GNRs + laser to a synergistic effect on PC-3 cell inhibition with longer incubation time (Figure S1).

Dox is a potent chemotherapy that has similar hydrophobicity and molecular weight with Doc. Dox was selected as 

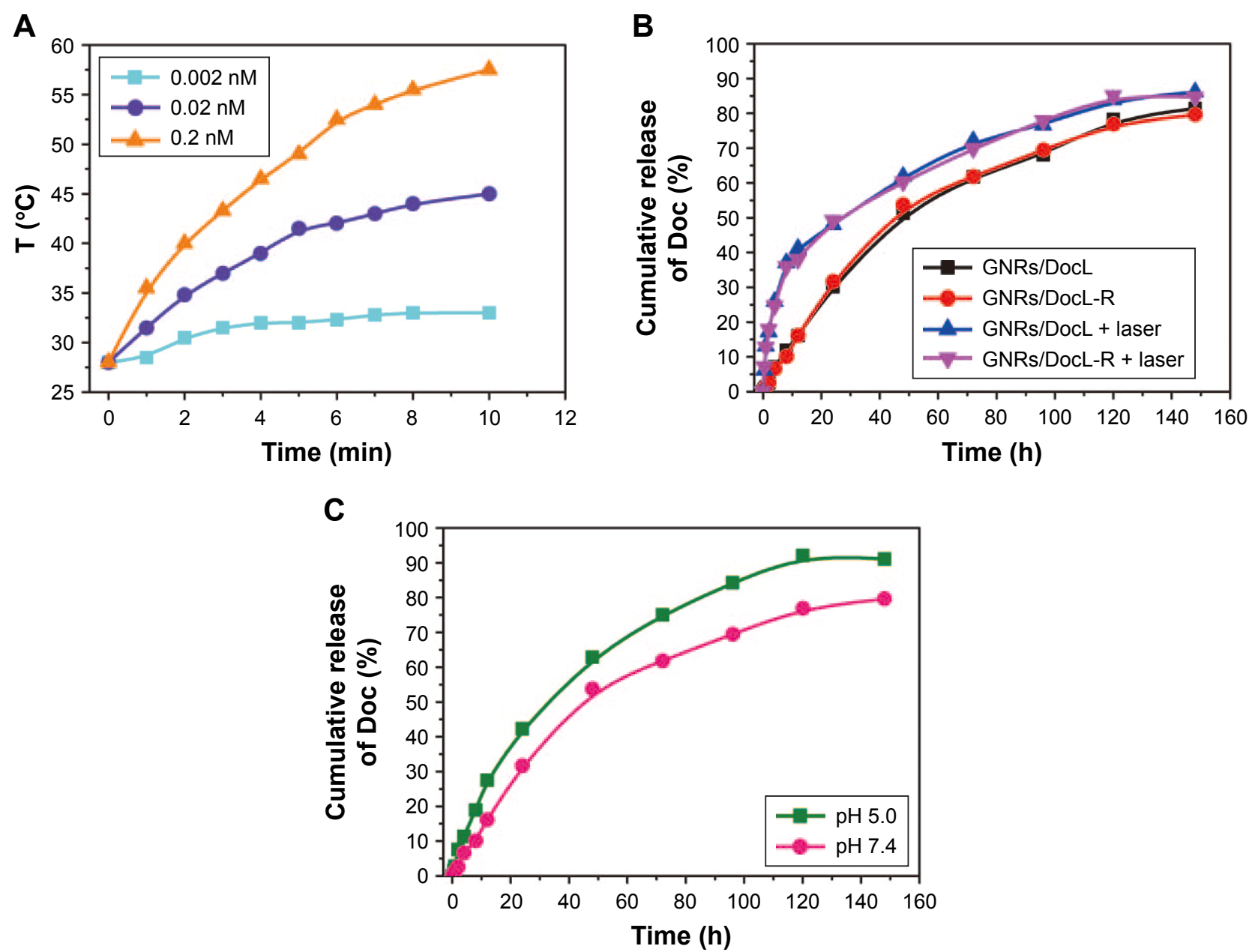

Figure 3 Doc release and thermal responses of GNRs/DocL-R.

Notes: (A) Thermal responses of GNRs/DocL-R to laser radiation (concentrations represented the GNR concentration in GNRs/DocL-R). (B) Doc release from the listed formulation with(out) laser radiation in $\mathrm{pH} 7.4 \mathrm{PBS}$ plus $0.5 \%$ Tween 80 . (C) Doc release from GNRs/DocL-Rin pH5.0 PBS plus $0.5 \%$ Tween 80 and pH7.4 PBS plus $0.5 \%$ Tween 80.

Abbreviations: Doc, docetaxel; GNRs, gold nanorods; GNRs/DocL-R, GNRs/Doc-liposome-RLT.

A

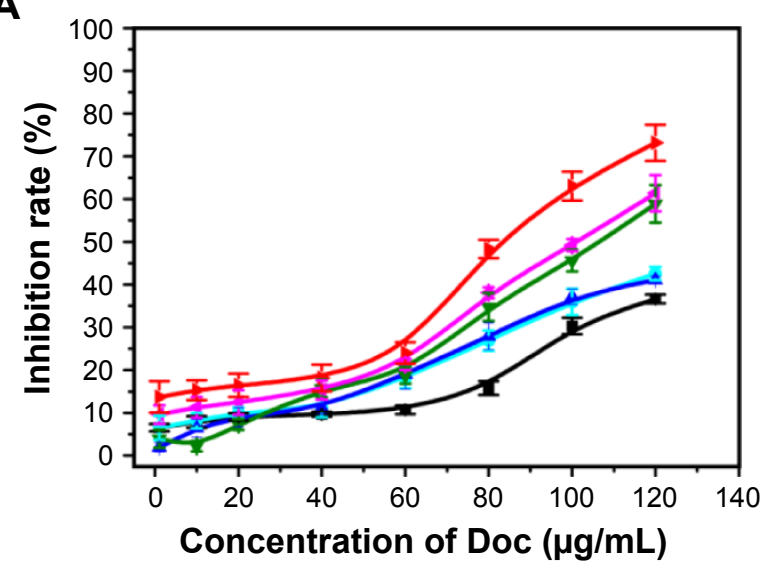

B

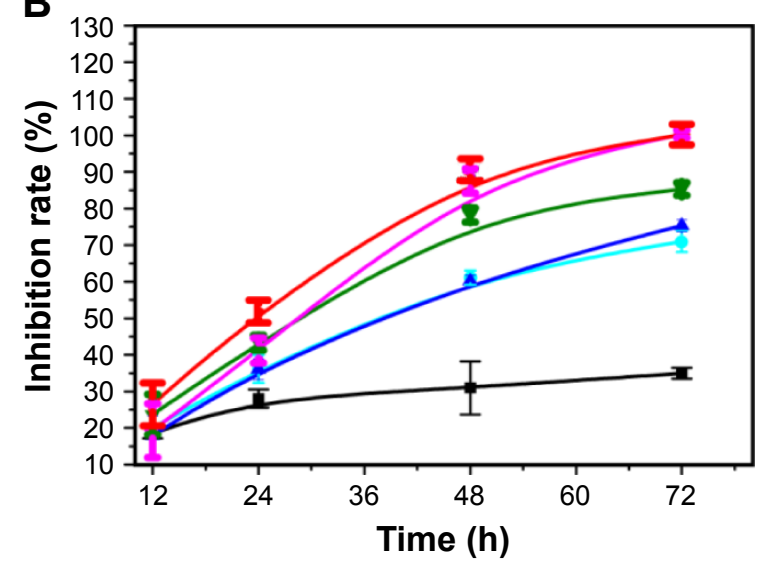

$\rightarrow$ Doc $\longrightarrow$ DocL $\longrightarrow$ GNRs/DocL $\multimap$ GNRs/DocL + laser $\leftarrow$ GNRs/DocL-R $\longrightarrow$ GNRs/DocL-R + laser

Figure 4 (Continued) 
C

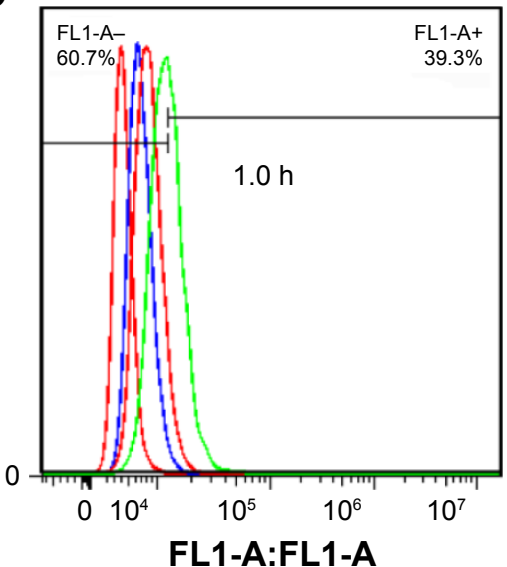

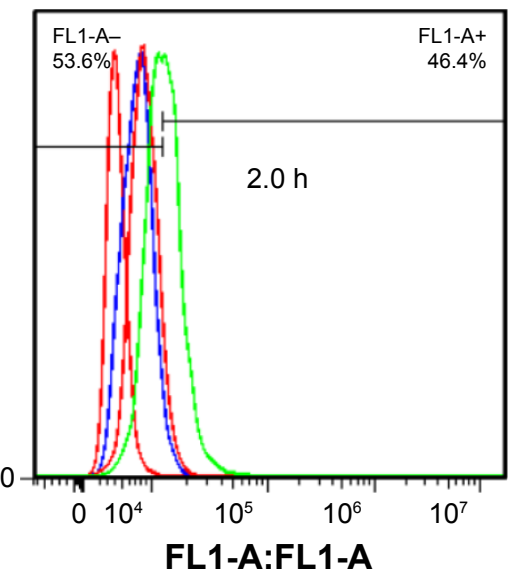

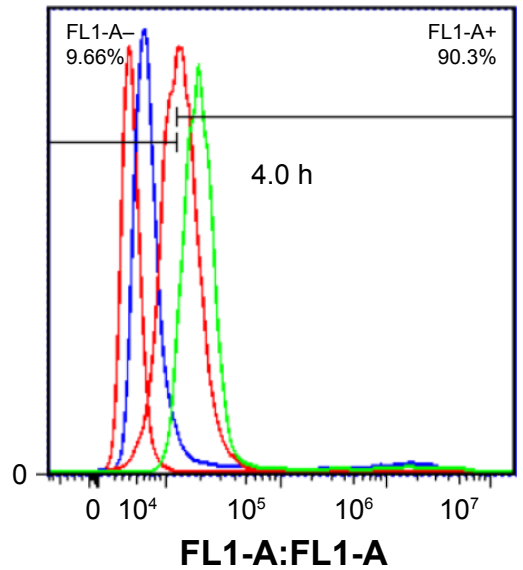

- Blank - Free Dox - GNRs/DoxL - GNRs/DoxL-R

D
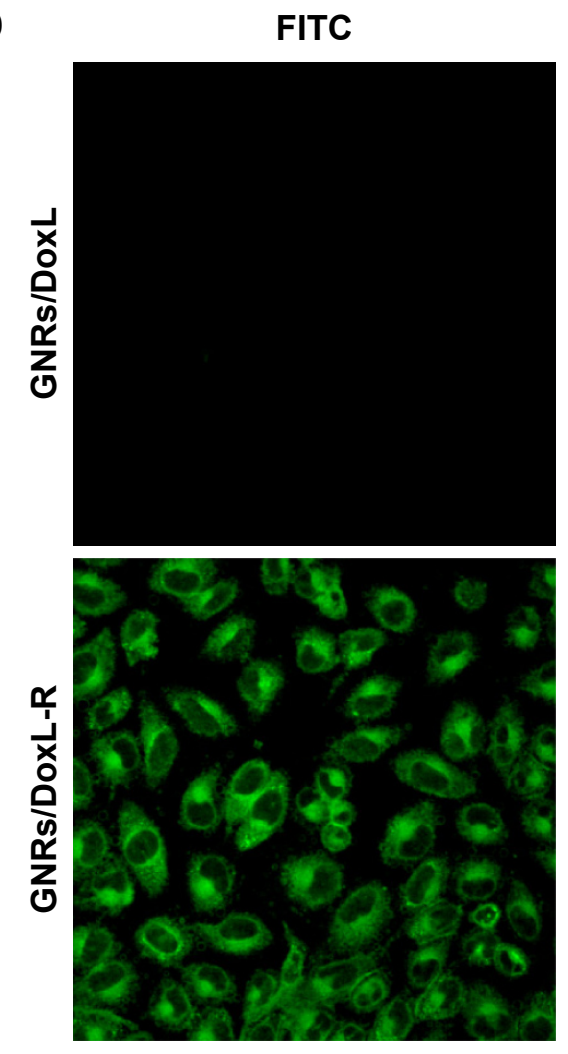

Dox
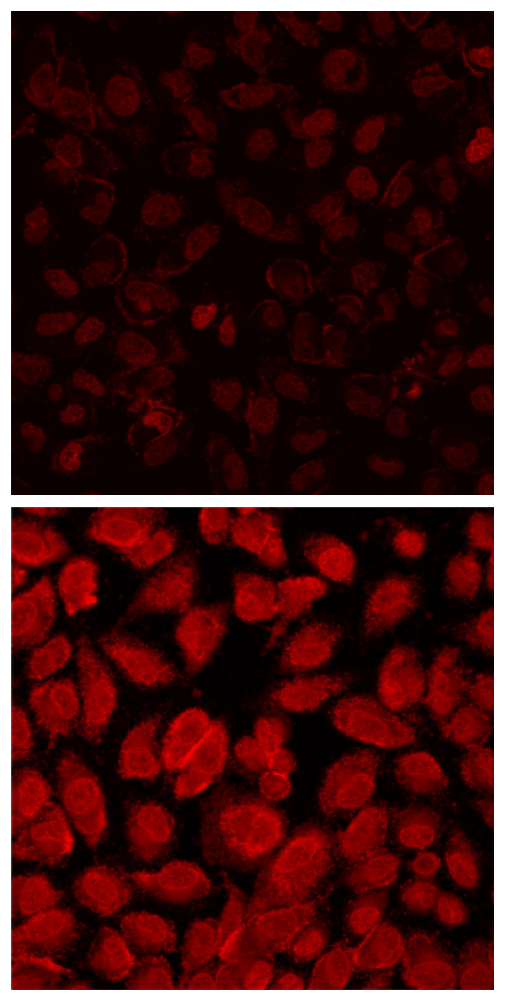

\section{Overlap}
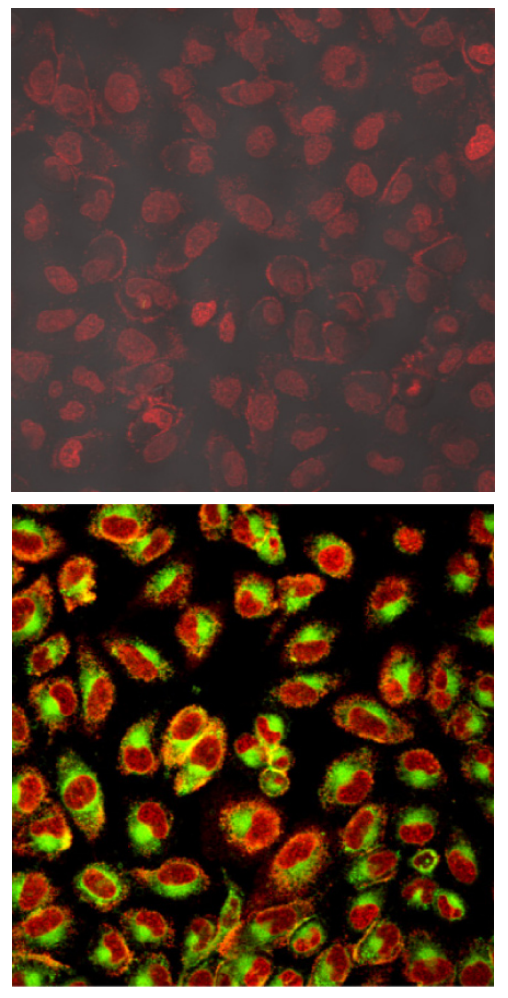

Figure 4 Evaluation of PC-3 cell inhibition by Doc and intracellular uptake of Dox.

Notes: (A) PC-3 cell inhibition rate by the listed treatments with increasing Doc concentration. (B) PC-3 cell inhibition rate by the listed treatments with increasing incubation period (the concentration of Doc for all treatments was $80 \mu \mathrm{g} / \mathrm{mL}$ ). (C) Flow cytometric histograms of intracellular uptake of Dox by PC-3 cells. (D) Confocal microscopy images of PC-3 cell after $4 \mathrm{~h}$ incubation with GNRs/DoxL and GNRs/DoxL-R. Red fluorescence and green fluorescence represented the location of Dox and GNRs/L-R, respectively. Orange fluorescence indicated the colocation of Dox and GNRs/L-R.

Abbreviations: Doc, docetaxel; Dox, doxorubicin; FITC, fluorescein isothiocyanate; GNRs, gold nanorods; PC-3, prostate cancer cell line.

fluorescent agent to investigate the intracellular uptake of the liposomes. Figure S2 shows that GNRs/DoxL-R-treated cells had a much stronger intracellular red fluorescence than free Dox and GNRs/DoxL, indicating a higher concentration of intracellular Dox using GNRs/DoxL-R. Flow cytometry was used to quantify the intracellular uptake of Dox.
The results showed that intracellular uptake rates of Dox using free Dox, GNRs/DoxL, and GNRs/DoxL-R were 2.5\%, $9.9 \%$, and $50.6 \%$, respectively, with $1 \mathrm{~h}$ incubation. After $4 \mathrm{~h}$ incubation, intracellular uptake rates of Dox using free Dox, GNRs/Dox liposomes, and GNRs/Dox-RLT liposomes were increased to $14.3 \%, 61.1 \%$, and $96.2 \%$, respectively 

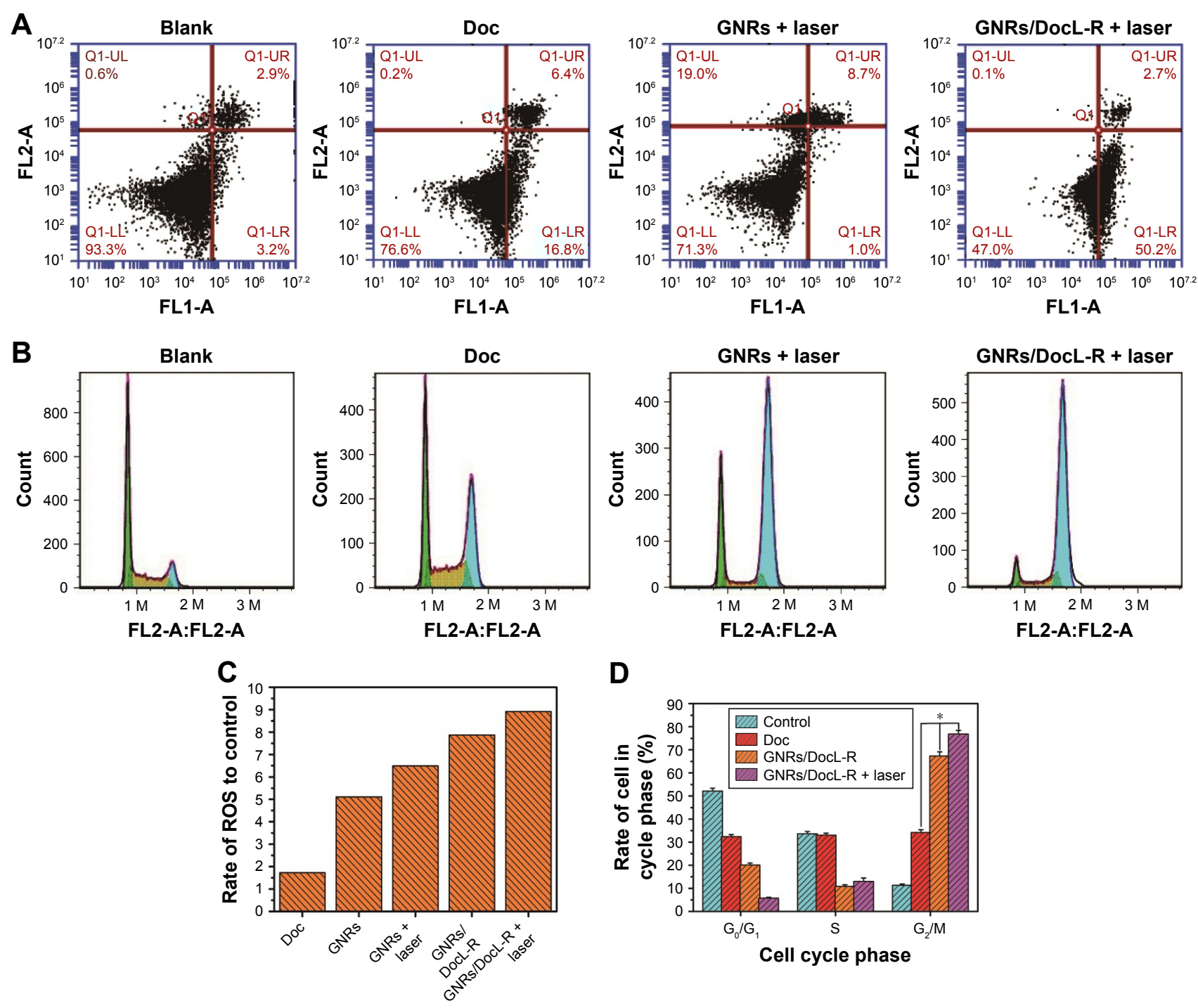

D

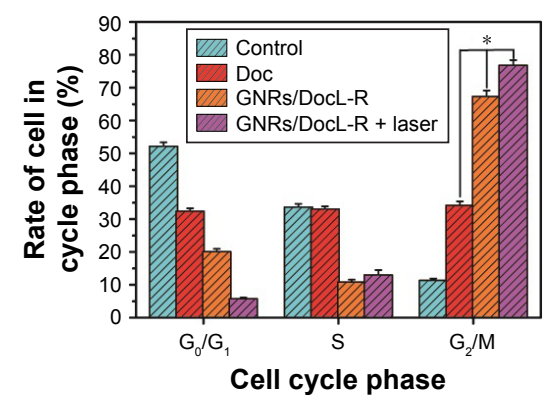

Figure 5 Flow cytometric analysis of anticancer mechanisms of listed treatments in vitro.

Notes: (A) Apoptotic statistics of PC-3 cells by the listed treatments. (B) Flow cytometry histograms of PC-3 cell cycle by the listed treatments. (C) Quantification of ROS in PC-3 cells that incubated with the listed treatments. (D) Cell cycle analysis of PC-3 cells after the listed treatments. Data are presented as mean \pm SD (N=3). *Doc vs GNRs/DocL-R vs GNRs/DocL-R + laser, $p<0.05$.

Abbreviations: Doc, docetaxel; GNRs, gold nanorods; GNRs/DocL-R, GNRs/Doc-liposome-RLT; PC-3, prostate cancer cell line; ROS, reactive oxygen species.

(Figure 4C). RLT was labeled with FITC, and thus the location of GNRs/DoxL-R in cells could be tracked by green fluorescence. As shown in Figure 4D, red fluorescence was observed in both cytoplasm and nucleus area of the cells, whereas green fluorescence was observed in the cytoplasm area of the cells. The overlapped cell image demonstrated the red nucleus and the yellowish cytoplasm.

\section{Flow cytometry analysis}

After $24 \mathrm{~h}$ of incubation with Doc, GNRs + laser, and GNRs/DocL-R + laser, cell apoptosis was analyzed by flow cytometry. As shown in Figure 5A, Doc caused $0.2 \%$ cell necrosis, $16.8 \%$ early apoptosis, and $6.4 \%$ late apoptosis;
GNRs + laser induced $19.0 \%$ cell necrosis, $1.0 \%$ early apoptosis, and $8.7 \%$ late apoptosis; GNRs/DocL-R + laser resulted in $0.1 \%$ cell necrosis, $50.2 \%$ early apoptosis, and $2.7 \%$ late apoptosis. GNRs/DocL-R + laser was significantly more potent to PC-3 cells than Doc plus GNRs + laser. The results of cell cycle analysis showed that blank PC-3 cells had around the half of cells in $\mathrm{G}_{0} / \mathrm{G}_{1}$ phase, preparing for DNA duplication and subsequent cell division. The PC-3 cells in $\mathrm{G}_{2} / \mathrm{M}$ phase were around $11.3 \% \pm 0.6 \%$. Incubation of the cells with Doc resulted in an increase in the cells in $\mathrm{G}_{2} / \mathrm{M}$ phase to $34.2 \% \pm 1.2 \%$. GNRs/DocL-R increased $\mathrm{G}_{2} / \mathrm{M}$ phase arrest to $67.4 \% \pm 1.8 \%$, whereas $\mathrm{G}_{0} / \mathrm{G}_{1}$ phase arrest and S phase arrest of PC-3 cells reduced to $20.0 \% \pm 0.9 \%$ and 

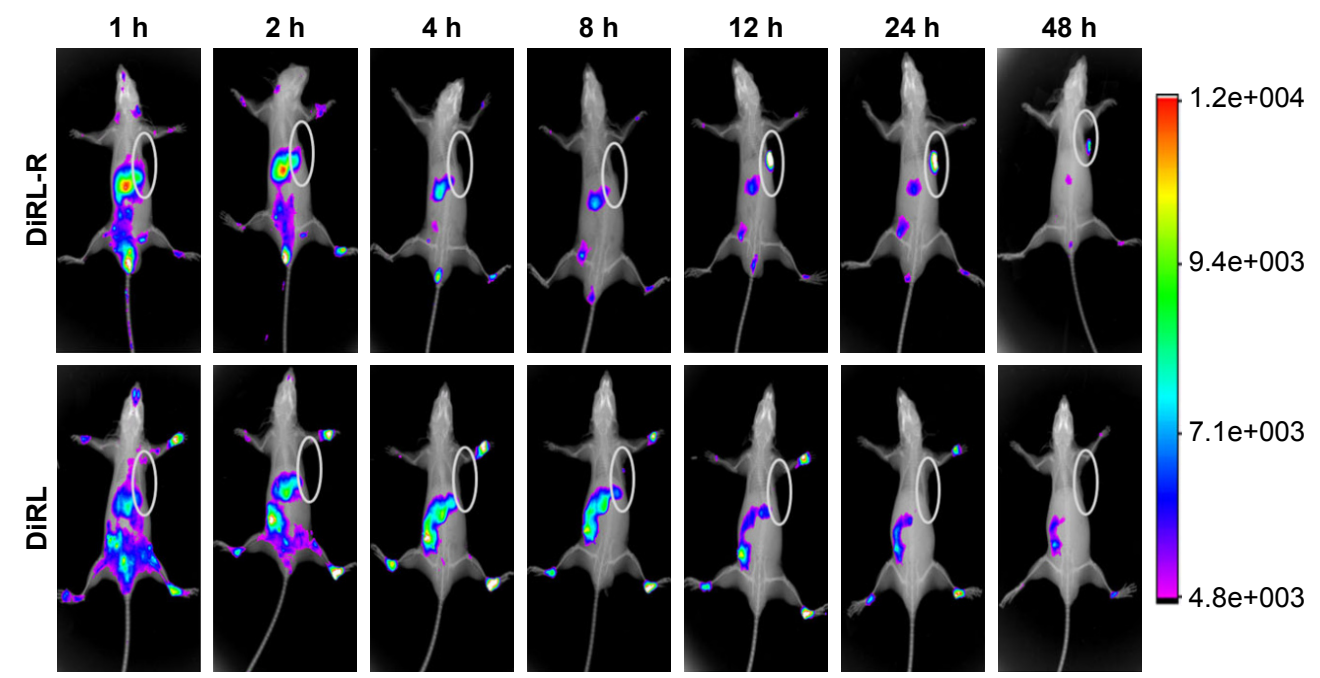

Figure 6 In vivo distribution of GNRs/DiRL-R and GNRs/DiRL after tail vein injection to nude mice.

Notes: Observed fluorescence indicated the location of DiR-encapsulated liposomes. The ellipses indicated the location of implanted PC-3 tumors.

Abbreviations: DiR iodide, I,I-dioctadecyl-3,3,3,3-tetramethylindotricarbocyanine iodide; DiRL, DiR liposomes; DiRL-R, DiR-RLT liposomes; GNRs, gold nanorods; PC-3, prostate cancer cell line.

$10.8 \% \pm 0.7 \%$, respectively. GNRs/DocL-R + laser reduced $\mathrm{G}_{0} / \mathrm{G}_{1}$ phase arrest to $5.7 \% \pm 0.4 \%$ and increased $\mathrm{G}_{2} / \mathrm{M}$ phase arrest to $76.8 \% \pm 1.6 \%$ (Figure $5 \mathrm{~B}$ and $\mathrm{D}$ ). Doc is a potent antimitotic chemotherapy and inhibits cell growth by $\mathrm{G}_{2} / \mathrm{M}$ phase arrest as shown in this study. GNRs/DocL-R + laser significantly enhanced the $\mathrm{G}_{2} / \mathrm{M}$ phase arrest of PC-3 cells compared to Doc. The existence of ROS is necessary to maintain the characteristics of cells. However, excess ROS will cause damage to intracellular macromolecules and lead to cell apoptosis. Doc could cause increased intracellular ROS. GNRs/DocL-R caused a much higher intracellular ROS because of its higher intracellular delivery of Doc. Laser radiation to cells also produced more intracellular ROS because of the heat generation by GNRs (Figure 5C).

\section{In vivo study}

RLT-modified lipid submicron emulsion increased the delivery of Doc to the tumor site of mice. ${ }^{18}$ To elucidate the dynamic distribution of the liposomes and the RLT-modified liposomes, DiR liposomes and DiR-RLT liposomes were tracked after tail vein injection to mice using In Vivo FX PRO. The fluorescence signal indicated the location of DiRencapsulated liposomes in vivo. DiR liposomes showed strong fluorescence in the liver and kidney and no fluorescence in PC-3 tumor-implanted site. RLT-modified DiR liposomes demonstrated strong fluorescence in PC-3 tumor-implanted site within $12 \mathrm{~h}$, and the fluorescent signal was maintained until $48 \mathrm{~h}$ (Figure 6). The results indicated that RLT-modified DiR liposomes could penetrate and accumulate in tumor sites. In vivo antitumor efficacy was evaluated by measuring the volume and weight of PC-3 tumor and calculating the inhibition rate of $\mathrm{PC}-3$ tumor. As shown in Figure 7A-C, all the listed treatments showed the reduced volume and weight of PC-3 tumor, and the increased inhibition rate of PC-3 tumor compared with Doc treatment. GNRs/DocL-R + laser resulted in the lowest volume and weight of PC-3 tumor, and the highest inhibition rate of PC-3 tumor. Body weight can be an indicator of mice health. As shown in Figure 7D, mice treated with Doc lost the most body weight at the end of treatment, whereas GNRs/Doc-RLT liposomes + laser treatment maintained the highest body weight of mice.

\section{Discussion}

Personalized and precise medicines are potential solutions for unmet medical needs. Nanomedicines that employ the latest drug delivery technologies are ideal candidates for personalized and precise medicines. The nanomedicines should be well designed and precisely constructed. The combination of gold nanoparticles and chemotherapy has been previously reported. For example, Yu et al have injected the physical mixture of a high thermosensitive liposome with GNRs to nude mice, and the results showed that GNRs not only facilitated co-accumulation of liposomes into tumor site but also triggered drug release from the liposomes. ${ }^{39} \mathrm{How}-$ ever, in Yu et al's work, the interaction between GNRs and liposomes was not clear. GNRs possibly interacted with the liposomes to achieve co-accumulation in tumor. Factors that affected the integrity of the physical mixture of GNRs and 

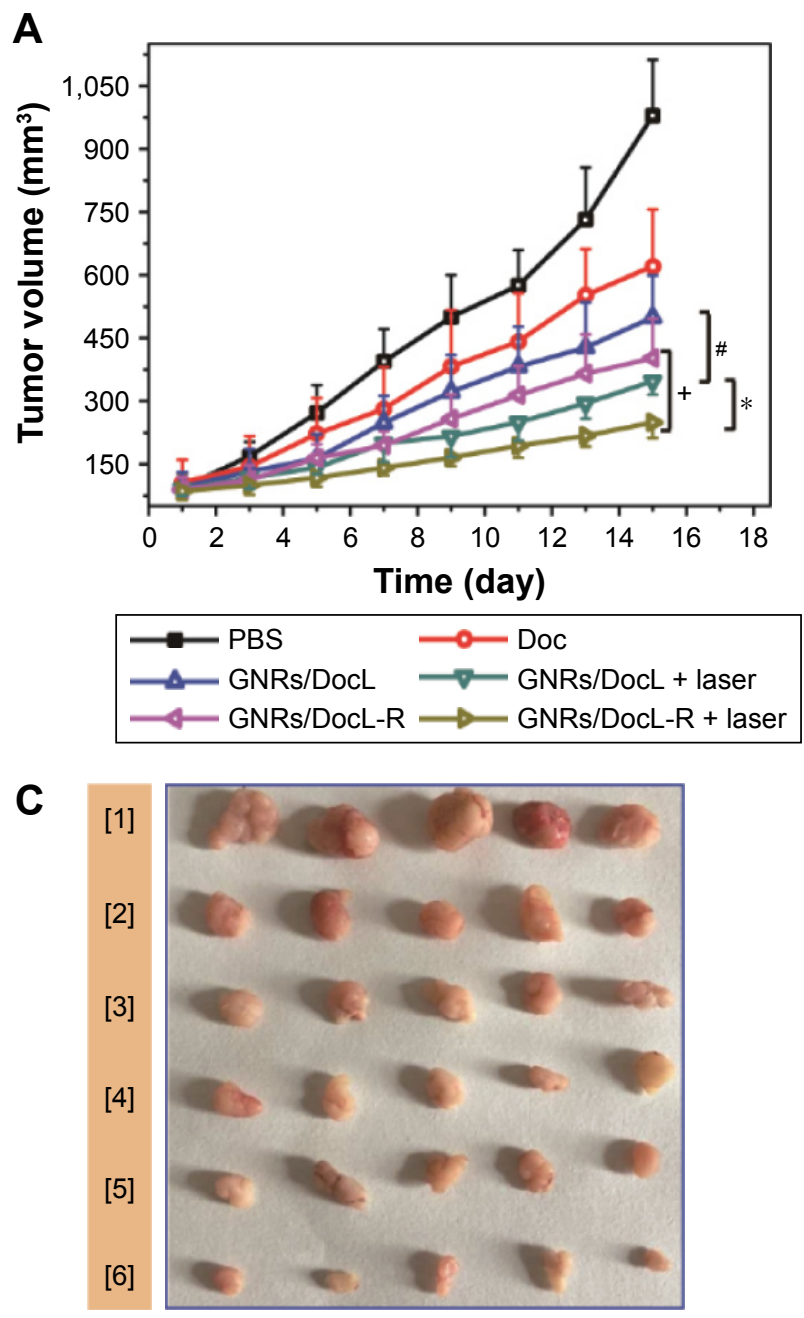

B
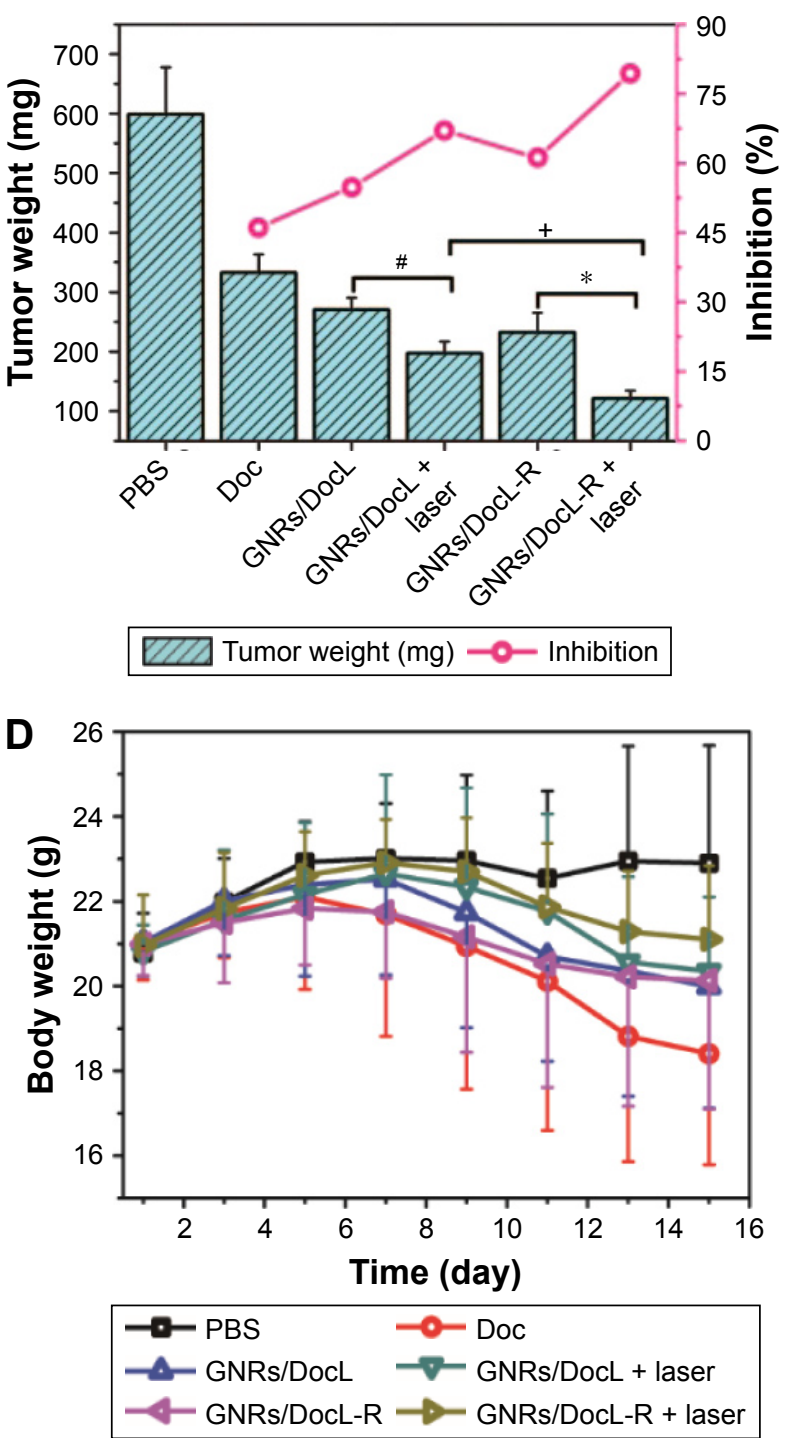

Figure 7 In vivo evaluation of the antitumor efficacy of the listed treatments.

Notes: (A) Tumor volume data during 15 days of treatment with the listed formulations. (B) Tumor weight and calculated tumor inhibition rate after 15 days of treatment with the listed formulations. (C) Tumor images after 15 days of treatment with the listed formulations (I-6: saline; Doc solution; GNRs/DocL; GNRs/DocL + laser; GNRs/ DocL-R; GNRs/DocL-R + laser, respectively). (D) Body weight data during 15 days of treatment with the listed formulations. Data are presented as mean $\pm \mathrm{SD}$ (N=5). ${ }^{+} \mathrm{GNRs} /$ DocL-R vs GNRs/DocL-R + laser, $p<0.05$. *GNRs/DocL + laser vs GNRs/DocL-R + laser, $p<0.01$. *GNRs/DocL vs GNRs/DocL + laser, $p<0.05$. Abbreviations: Doc, docetaxel; GNRs, gold nanorods; GNRs/DocL-R, GNRs/Doc-liposome-RLT.

liposomes might reduce antitumor efficacy. Kang and $\mathrm{Ko}^{26}$ also developed lipid-covered gold nanoparticles and GNRs that contained Doc in the lipids. Compared to liposomes, monolayered lipids had limited drug LC. Both studies showed enhanced tumor inhibition via the combined use of gold nanoparticles and chemotherapy. However, drug release from the two systems was too fast for clinical application. In sum, the composition and interaction of a precise nanomedicine should be well characterized. Precise nanomedicines should be stable and reliable, can load sufficient drugs, can achieve sustained/ controlled release based on the treatment demands, etc.
In this study, Doc was loaded into the lipophilic bilayer of the liposomes, and GNRs were encapsulated into the core of the liposomes. Compared with the physical mixture of GNRs/ gold nanoparticles and liposomes, ${ }^{25,27}$ and the liposome-GNR hybrids, ${ }^{28-30}$ GNRs/DocL-R could protect GNRs and Doc from physical environment, ensure simultaneous in vivo behavior of the liposomes and GNRs, and enhance GNR-triggered Doc release from the liposomes. The issue of drug leakage from the liposomes was improved compared to previous studies. Around $15 \%$ of drug was released within $12 \mathrm{~h}$, at which significant accumulation of DiRL-R had been observed at tumor 
site (Figure 6). Once GNRs/DocL-R arrived tumor site, drugs needed to be released to kill tumor. Therefore, the drug release profile could meet the need for this study. For the long-term storage, GNRs/DocL-R can be lyophilized and stored in dry place. Laser radiation increased local temperature and might trigger Doc release. Mathiyazhakan et $\mathrm{al}^{31}$ proposed that gold nanoparticles triggered drug release by inducing phase transition of the liposomes as well as the generation of microbubble cavitation. The phase transition temperature of HSPC and SPC were $50^{\circ} \mathrm{C}$ and below $41^{\circ} \mathrm{C}$, respectively. ${ }^{32}$ In this study, laser radiation to GNRs generated a local temperature higher than $50^{\circ} \mathrm{C}$ (Figure $3 \mathrm{C}$ ), which might increase membrane fluidity of the liposomes and accelerate Doc release. Increased Doc release induced the enhanced in vitro and in vivo anticancer efficacy (Figures 4, 5, and 7).

Chol is an essential component for the synthesis of new cell membrane. LDLRs that response for the transportation of chol are thus highly active in tumor cells. Liposomes are generally believed to be taken via two steps: adsorption onto the cell surface and endocytosis. Schaefer et $\mathrm{al}^{33}$ reported a clathrin-dependent internalization of unmodified liposomepolyethyleneimine complexes by SKOV-3 cells. In this study, DSPE-PEG (2000)-Mal was modified at a molar ratio of $0.375 \%$ of total lipids in the liposomes. The low modification rate was consistent with the previous report from $\mathrm{Li}$ and Takeoka. ${ }^{34}$ The purpose was to maintain an original physical characteristics, such as size, lipid compositions, drug-tolipid ratio, drug encapsulation efficiency, stability, and zeta potential, of the liposomes. $\mathrm{Li}$ and Takeoka ${ }^{35}$ showed the enhanced cellular uptake of liposomes via thiol-mediated transport with the addition of low concentrated DSPE-PEG (2000)-Mal, which was consistent with our results that the low-level modification of RLT to the liposomes increased intracellular uptake. PEGylation prolongs the in vivo circulation of liposomes but attenuates their endocytosis by cells. ${ }^{36}$ RLT was used to enhance LDLR-mediated endocytosis and assist endo-lysosomal escape in cells. ${ }^{14-16}$

Doc is an anti-microtubule agent that induces cell apoptosis and cell cycle arrest via the disorganization of microtubule structure. ${ }^{37}$ Cell responses to PTT are mainly cell injury/death via necrosis. ${ }^{38}$ In this study, Doc mainly caused PC-3 cell apoptosis, whereas GNRs + laser resulted in necrosis (Figure 5A). However, only significant apoptosis was observed using GNRs/DocL-R + laser. The result was different from our previous study that the addition of laser radiation to Dox/DNA complexed GNR system (Dox/DNAGNRs-PEG/R) mainly led to enhanced cell necrosis. ${ }^{3}$ The contrary results might be caused by the different structures of the two drug delivery systems. Because of the central location of GNRs, heating generated by GNRs/DocL-R + laser might induce the disruption of liposomes and the release of Doc, whereas laser-radiated Dox/DNA-GNRs-PEG/R released the heating directly to the environment. Doc increased $M$ phage arrest by destroying microtubules that were essential for cell division. GNRs/DocL-R could significantly increase $\mathrm{M}$ phage arrest of PC-3 cells due to the enhanced and sustained intracellular delivery of Doc. The cell apoptosis and cell cycle arrest results explained the significantly reduced in vivo tumor weight and volume (Figure 7C).

The current study developed a promising therapy for combating PC. To elucidate in vivo behavior of GNRs/DocL-R, pharmacokinetic (PK) study was under investigation in our laboratory. Preliminary data were consistent with in vivo distribution of GNRs/DocL-R (Figure 6). Mice treated with GNRs/ DocL-R showed a significantly higher concentration and longer circulation of Doc in the blood plasma compared with Doc and GNRs/DocL (data unpublished). Despite high targeting to tumor, significant liver accumulation of DiRL-R was observed within $0-2 \mathrm{~h}$ after injection. Most liposomes have the issue of high accumulation in the liver, which may disrupt the liposomes and cause drug leakage from the liposomes. Further PK study will quantify Doc concentration in the liver, and the liposomes will be modified to avoid the metabolism by liver.

\section{Conclusion}

In this study, a multifunctional liposome was developed for improved anticancer therapy. Doc and GNRs were loaded into the liposomes as chemotherapy and thermotherapy agents. The liposomes achieved a prolonged and sustained release of Doc. Laser radiation to GNRs led to Doc release from the liposomes in vitro and in vivo. Tumor targeting was increased by modifying the liposomes with RLT. The developed GNRs/DocL-R showed a promising anticancer efficacy and low toxicity in in vitro and in vivo evaluation. The results suggested that the stable and easily prepared GNRs/DocL-R could be an efficient and sustained therapy for PC. Thermal therapy using laser radiation further enhanced anticancer efficacy via increased release and intracellular delivery of Doc to PC-3 cells. Future work will focus on the PK study of GNRs/DocL-R to quantify the distribution and elimination of Doc and confirm the potential of GNRs/ DocL-R for clinical use.

\section{Acknowledgment}

Financial support was from National Natural Science Foundation of China (NSFC No 81372406). 


\section{Disclosure}

The authors report no conflicts of interest in this work.

\section{References}

1. Huang XH, El-Sayed IH, Qian W, El-Sayed MA. Cancer cell imaging and photothermal therapy in the near-infrared region by using gold nanorods. J Am Chem Soc. 2006;128(6):2115-2120.

2. Tong L, Zhao Y, Huff TB, Hansen MN, Wei A, Cheng J-X. Gold nanorods mediate tumor cell death by compromising membrane integrity. Adv Mater. 2007;19(20):3136.

3. Zhang N, Li S, Hua H, et al. Low density lipoprotein receptor targeted doxorubicin/DNA-gold nanorods as a chemo- and thermo-dual therapy for prostate cancer. Int J Pharm. 2016;513(1-2):376-386.

4. Huang HC, Barua S, Kay DB, Rege K. Simultaneous enhancement of photothermal stability and gene delivery efficacy of gold nanorods using polyelectrolytes. ACS Nano. 2009;3(10):2941-2952.

5. Huang HC, Rege K, Heys JJ. Spatiotemporal temperature distribution and cancer cell death in response to extracellular hyperthermia induced by gold nanorods. ACS Nano. 2010;4(5):2892-2900.

6. Choi WI, Kim JY, Kang C, Byeon CC, Kim YH, Tae G. Tumor regression in vivo by photothermal therapy based on gold-nanorod-loaded, functional nanocarriers. ACS Nano. 2011;5(3):1995-2003.

7. Helmchen F, Denk W. Deep tissue two-photon microscopy. Nat Methods. 2005;2(12):932-940.

8. Kuo WS, Chang CN, Chang YT, et al. Gold nanorods in photodynamic therapy, as hyperthermia agents, and in near-infrared optical imaging. Angew Chem Int Edit. 2010;49(15):2711-2715.

9. He XM, Wolkers WF, Crowe JH, Swanlund DJ, Bischof JC. In situ thermal denaturation of proteins in dunning AT-1 prostate cancer cells: implication for hyperthermic cell injury. Ann Biomed Eng. 2004;32(10): 1384-1398.

10. Cortes JE, Pazdur R. Docetaxel. J Clin Oncol. 1995;13(10): 2643-2655.

11. Shen S, Tang H, Zhang X, et al. Targeting mesoporous silicaencapsulated gold nanorods for chemo-photothermal therapy with nearinfrared radiation. Biomaterials. 2013;34(12):3150-3158.

12. Allen TM, Cullis PR. Liposomal drug delivery systems: from concept to clinical applications. Adv Drug Deliv Rev. 2013;65(1):36-48.

13. Chen Y, Hughes-Fulford M. Human prostate cancer cells lack feedback regulation of low-density lipoprotein receptor and its regulator, SREBP2. Int J Cancer. 2001;91(1):41-45.

14. Hayavi S, Halbert GW. Synthetic low-density lipoprotein, a novel biomimetic lipid supplement for serum-free tissue culture. Biotechnol Prog. 2005;21(4):1262-1268.

15. Nikanjam M, Blakely EA, Bjornstad KA, Shu X, Budinger TF, Forte TM. Synthetic nano-low density lipoprotein as targeted drug delivery vehicle for glioblastoma multiforme. Int J Pharm. 2007;328(1):86-94.

16. Nikanjarn M, Gibbs AR, Hunt A, Budinger TF, Forte TM. Synthetic nano-LDL with paclitaxel oleate as a targeted drug delivery vehicle for glioblastoma multiforme. J Control Release. 2007;124(3):163-171.

17. Zhang N, Tao J, Hua HY, Sun PC, Zhao YX. Low-density lipoprotein peptide-combined DNA nanocomplex as an efficient anticancer drug delivery vehicle. Eur J Pharm Biopharm. 2015;94:20-29.

18. Zhang N, Miao J, Sun P, et al. Pharmacokinetics, tissue distribution and anti-tumor effect of low density lipoprotein peptide conjugated submicron emulsions. Biomed Pharmacother. 2016;82:614-619.

19. Orendorff CJ, Murphy CJ. Quantitation of metal content in the silverassisted growth of gold nanorods. J Phys Chem B. 2006;110(9): 3990-3994.

20. Nikoobakht B, El-Sayed MA. Preparation and growth mechanism of gold nanorods (NRs) using seed-mediated growth method. Chem Mate. 2003;15(10):1957-1962.
21. Sau TK, Murphy CJ. Seeded high yield synthesis of short Au nanorods in aqueous solution. Langmuir. 2004;20(15):6414-6420.

22. Shariat S, Badiee A, Jalali SA, et al. P5 HER2/neu-derived peptide conjugated to liposomes containing MPL adjuvant as an effective prophylactic vaccine formulation for breast cancer. Cancer Lett. 2014; 355(1):54-60.

23. Chen Z, He N, Chen M, Zhao L, Li X. Tunable conjugation densities of camptothecin on hyaluronic acid for tumor targeting and reductiontriggered release. Acta Biomater. 2016;43:195-207.

24. Chu S, Tang C, Yin C. Effects of mannose density on in vitro and in vivo cellular uptake and RNAi efficiency of polymeric nanoparticles. Biomaterials. 2015;52:229-239.

25. Chen P, Huang N-T, Chung M-T, Cornell TT, Kurabayashi K. Labelfree cytokine micro- and nano-biosensing towards personalized medicine of systemic inflammatory disorders. Adv Drug Deliv Rev. 2015;95: 90-103.

26. Kang JH, Ko YT. Lipid-coated gold nanocomposites for enhanced cancer therapy. Int $J$ Nanomedicine. 2015;10(Spec Iss):33-45.

27. Guo HY, Kim JC. Photothermally induced release from liposome suspended in mixture solution of gold nanoparticle and thermo-sensitive polymer. Colloid Surf A. 2015;469:73-82.

28. Reyes-Ortega F, Cifuentes A, Rodriguez G, et al. Bioactive bilayered dressing for compromised epidermal tissue regeneration with sequential activity of complementary agents. Acta Biomater. 2015;23:103-115.

29. Taruttis A, Lozano N, Nunes A, et al. siRNA liposome-gold nanorod vectors for multispectral optoacoustic tomography theranostics. Nanoscale. 2014;6(22):13451-13456.

30. Lozano N, Al-Jamal WT, Taruttis A, et al. Liposome-gold nanorod hybrids for high-resolution visualization deep in tissues. $J \mathrm{Am}$ Chem Soc. 2012;134(32):13256-13258.

31. Mathiyazhakan M, Yang Y, Liu Y, et al. Non-invasive controlled release from gold nanoparticle integrated photo-responsive liposomes through pulse laser induced microbubble cavitation. Colloids Surf B Biointerfaces. 2015;126:569-574.

32. Chen J, Yan GJ, Hu RR, et al. Improved pharmacokinetics and reduced toxicity of brucine after encapsulation into stealth liposomes: role of phosphatidylcholine. Int J Nanomedicine. 2012;7:3567-3577.

33. Schaefer J, Hoebel S, Bakowsky U, Aigner A. Liposome-polyethylenimine complexes for enhanced DNA and siRNA delivery. Biomaterials. 2010;31(26):6892-6900.

34. Li T, Takeoka S. A novel application of maleimide for advanced drug delivery: in vitro and in vivo evaluation of maleimide-modified $\mathrm{pH}-$ sensitive liposomes. Int J Nanomedicine. 2013;8:3855-3866.

35. Li T, Takeoka S. Enhanced cellular uptake of maleimide-modified liposomes via thiol-mediated transport. Int J Nanomedicine. 2014;9: 2849-2861.

36. Miller CR, Bondurant B, McLean SD, McGovern KA, O'Brien DF. Liposome-cell interactions in vitro: effect of liposome surface charge on the binding and endocytosis of conventional and sterically stabilized liposomes. Biochemistry. 1998;37(37):12875-12883.

37. Wang LG, Liu XM, Kreis W, Budman DR. The effect of antimicrotubule agents on signal transduction pathways of apoptosis: a review. Cancer Chemother Pharmacol. 1999;44(5):355-361.

38. Fernandez Cabada T, Sanchez Lopez de Pablo C, Martinez Serrano A, del Pozo Guerrero F, Serrano Olmedo JJ, Ramos Gomez M. Induction of cell death in a glioblastoma line by hyperthermic therapy based on gold nanorods. Int J Nanomedicine. 2012;7:1511-1523.

39. Yu M, Guo F, Tan F, Li N. Dual-targeting nanocarrier system based on thermosensitive liposomes and gold nanorods for cancer thermochemotherapy. J Control Release. 2015;215:91-100. 


\section{Supplementary materials Materials and methods}

Synthesis and characterization of gold nanorods (GNRs)

GNRs were synthesized by using a modified seed-mediated growth method in aqueous solution. The solutions were prepared and stored in the dark. To prepare "gold seed solution," $5 \mathrm{~mL}$ of $5 \times 10^{-4} \mathrm{M} \mathrm{HAuCl}_{4}$ was added to $5 \mathrm{~mL}$ $0.2 \mathrm{M}$ cetyltrimethyl-ammonium bromide $(\mathrm{CTAB})$ at $25^{\circ} \mathrm{C}$ and mixed rapidly until the color of the solution turned golden brown. About $600 \mu \mathrm{L}$ of ice-cold $0.01 \mathrm{M} \mathrm{NaBH}_{4}$ was added to the golden brown solution under vigorous stirring for at least $2 \mathrm{~min}$. The color of the solution turned dark brown, and the seed solution was kept at $28^{\circ} \mathrm{C}$ for $3 \mathrm{~h}$ before later usage. To prepare "gold growth solution," $200 \mu \mathrm{L}$ of freshly prepared $\mathrm{AgNO}_{3}$ solution $(4 \mathrm{mM})$ was added to $5 \mathrm{~mL} 0.2 \mathrm{M}$ $\mathrm{CTAB}$ at $25^{\circ} \mathrm{C}$. About $5 \mathrm{~mL}$ of $1 \times 10^{-3} \mathrm{M} \mathrm{HAuCl}_{4}$ was then added to the mixture, and the solution changed to golden brown after mixing, and $70 \mu \mathrm{L}$ of $0.0788 \mathrm{M}$ ascorbic acid was added under vigorous stirring until the color of the solution became transparent. Gold seed solution $(1.1 \mathrm{~mL})$ was added and mixed well with the gold growth solution $(10.27 \mathrm{~mL})$. The mixture was settled for $5 \mathrm{~min}$, and the solution color turned dark red. GNRs were synthesized by incubating the mixture at $30^{\circ} \mathrm{C}$ overnight. GNR mixture was then processed with centrifugation at 7,000 rpm for $15 \mathrm{~min}$. Supernatant was collected and centrifuged at 14,000 rpm for $15 \mathrm{~min}$. GNR pellet was obtained and suspended with purified water. One more centrifugation was conducted (14,000 rpm for $15 \mathrm{~min}$ ), and the final gold pellet was collected for later studies.

Size and zeta potential of GNRs were analyzed by Zetasizer Nano ZS90 (Malvern Instruments, Malvern, UK). Morphology of GNRs was observed by transmission electron microscopy (TEM; TecnaiG20; FEI, Hillsboro, OR, USA). Briefly, fresh samples were diluted in Millipore water and mixed well. The samples were then transferred into cuvette for GNR size and zeta potential measurements. To visualize GNR morphology, a fresh sample was placed on copper grids with film and settled for $1 \mathrm{~min}$. Excess liquid was absorbed by paper, and the sample was air dried for TEM examination.

\section{Preparation of I, I-dioctadecyl-3,3,3,3-}

tetramethylindotricarbocyanine (DiR) solution

DiR $(2 \mathrm{mg})$ was weighed and placed in $1.5 \mathrm{~mL}$ enpendoff tube. Ethanol $(600 \mu \mathrm{L})$ was added to the EP tube. DiR solution was vortexed before usage.

\section{Preparation of GNRs/DiR liposomes and GNRs/DiR-RLT liposomes}

Cholesterol (chol; $20 \mathrm{mg}$ ), soy phosphatidylcholine (SPC; $150 \mathrm{mg}$ ), hydrogenated SPC (HSPC; $5 \mathrm{mg}$ ), and 1,2distearoyl-sn-glycero-3-phosphoethanolamine-conjugated polyethylene glycol (DSPE-PEG (2000)-Mal; $2.5 \mathrm{mg}$ ) were dissolved in $15 \mathrm{~mL}$ chloroform. DiR ethanol solution $(120 \mu \mathrm{L})$ was added to the mixture under sonication. Sonication was continued for $15 \mathrm{~min}$ in the dark. Chloroform was then removed by rota-evaporation, and the lipid solution was dried to a thin and transparent film at the bottom of the flask. GNR solution $(0.4 \mathrm{nM}, 4 \mathrm{~mL})$ was then added to the flask to hydrate and dissolve the film by sonication. The flask was then sonicated in ice bath for 40 times $(200 \mathrm{~W})(3 \mathrm{~s}, 3 \mathrm{~s})$ and centrifuged at $8,000 \mathrm{rpm}$ for $10 \mathrm{~min}$. Supernatant was obtained as GNRs/DiR liposomes and kept at $4^{\circ} \mathrm{C}$. To prepare GNRs/DiR-RLT liposomes, the supernatant was mixed with RLT solution. The mixture was vortexed for $1 \mathrm{~min}$ and shaken for $12 \mathrm{~h}$ at room temperature. The obtained GNRs/ DiR-RLT liposomes were kept at $4^{\circ} \mathrm{C}$.

\section{High-performance liquid chromatography (HPLC) for the quantification of reacted RLT}

Liposomes prepared with different DSPE-PEG (2000)Mal:RLT ratios were injected to and analyzed by HPLC (Agilent 1100, flow rate: $1.0 \mathrm{~mL} / \mathrm{min}$, mobile phase: acetonitrile: water 20.8\%: $79.2 \%$ (0.05\% trifluoroacetic acid), column: Diamonsil ${ }^{\mathrm{TM}} \mathrm{C} 18,4.6 \times 200 \mathrm{~mm}, 5 \mu \mathrm{m}$, detection wavelength: $215 \mathrm{~nm}$ and temperature: $25^{\circ} \mathrm{C}$ ). Unreacted RLT was calculated based on the area under the peak. 
Table SI The influence of GNR concentration on particle size, PDI, zeta potential, and appearance (N=3)

\begin{tabular}{lllll}
\hline GNRs $(\mathbf{n M})$ & Particle size $(\mathbf{n m})$ & PDI & Zeta potential $(\mathbf{m V})$ & Appearance \\
\hline 0.635 & $158.2 \pm 1.29$ & $0.26 \pm 0.08$ & $-20.5 \pm 4.92$ & Aggregation of GNRs after a few days \\
0.4 & $163.1 \pm 1.47$ & $0.29 \pm 0.05$ & $-26.1 \pm 3.86$ & Little aggregation of GNRs after a few days \\
0.2 & $161.6 \pm 1.9$ & $0.27 \pm 0.13$ & $-32.3 \pm 3.6 \mathrm{I}$ & No aggregation \\
\hline
\end{tabular}

Abbreviations: GNRs, gold nanorods; PDI, polydispersity index.

Table S2 The influence of SPC:HSPC on particle size, PDI, zeta potential, densification of film, and stability of liposomes ( $\mathrm{N}=3$ )

\begin{tabular}{llllll}
\hline SPC:HSPC $(\mathbf{m o l} / \mathbf{m o l})$ & Particle size $(\mathbf{n m})$ & PDI & Zeta potential $(\mathbf{m V})$ & Densification of film & Stability \\
\hline $50: 1$ & $136.1 \pm 2.72$ & $0.78 \pm 0.10$ & $-21.5 \pm 1.64$ & Loose & Unstable \\
$40: 1$ & $140 \pm 1.73$ & $0.49 \pm 0.08$ & $-26.1 \pm 0.97$ & Loose & Semi-stable \\
$1: 30$ & $169.4 \pm 1.62$ & $0.250 \pm 0.05$ & $-32.8 \pm 1.04$ & Compact & Stable \\
$1: 40$ & $204 \pm 2.18$ & $0.28 \pm 0.09$ & $-31.4 \pm 2.09$ & Compact & Stable \\
I:50 & $214 \pm 1.83$ & $0.41 \pm 0.13$ & $-24.8 \pm 0.57$ & Compact & Semi-stable \\
\hline
\end{tabular}

Abbreviations: HSPC, hydrogenated SPC; PDI, polydispersity index; SPC, soy phosphatidylcholine.

Table S3 The influence of chol addition on particle size, PDI, zeta potential, and stability of liposomes $(\mathrm{N}=3)$

\begin{tabular}{lllll}
\hline (H)SPC:chol $(\mathbf{m o l} / \mathbf{m o l})$ & Particle size $(\mathbf{n m})$ & PDI & Zeta potential $(\mathbf{m V})$ & Stability \\
\hline $10: 1$ & $145.1 \pm 2.06$ & $0.37 \pm 0.09$ & $-37.2 \pm 0.69$ & Unstable \\
$8: 1$ & $152.8 \pm 1.47$ & $0.21 \pm 0.07$ & $-34.0 \pm 1.19$ & Stable \\
$6: 1$ & $190.4 \pm 1.62$ & $0.32 \pm 0.05$ & $-30.8 \pm 1.03$ & Semi-stable \\
\hline
\end{tabular}

Note: $(H) S P C=S P C+$ HSPC.

Abbreviations: chol, cholesterol; HSPC, hydrogenated SPC; PDI, polydispersity index; SPC, soy phosphatidylcholine.

Table S4 The influence of molar ratio between DSPE-PEG (2000)-Mal and RLT on the reaction rate of RLT (N=3)

DSPE-PEG (2000)-Mal:RLT

$\begin{array}{ll}1: 1 & 29 \\ 2: 1 & 71 \\ 3: 1 & 90\end{array}$

Note: DSPE-PEG (2000)-Mal, I,2-distearoyl-sn-glycero-3-phosphoethanolamine-conjugated polyethylene glycol.

Table S5 The influence of ultrasonic condition on particle size, PDI, zeta potential, and appearance ( $\mathrm{N}=3$ )

\begin{tabular}{lllll}
\hline $\begin{array}{l}\text { Power and time } \\
\text { of sonication }\end{array}$ & $\begin{array}{l}\text { Particle } \\
\text { size }(\mathbf{n m})\end{array}$ & PDI & $\begin{array}{l}\text { Zeta } \\
\text { potential }(\mathbf{m V})\end{array}$ & Appearance \\
\hline No sonication & $237.2 \pm 2.15$ & $0.68 \pm 0.14$ & $-30.2 \pm 2.61$ & Translucent viscous liquid \\
$100 \mathrm{~W}, 120 \mathrm{~s}$ & $210.5 \pm 1.93$ & $0.59 \pm 0.15$ & $-29.6 \pm 1.94$ & Good transparence and dispersity \\
$200 \mathrm{~W}, 120 \mathrm{~s}$ & $203.8 \pm 2.37$ & $0.37 \pm 0.09$ & $-30.9 \pm 2.08$ & Good transparence and dispersity \\
$300 \mathrm{~W}, 120 \mathrm{~s}$ & $179.2 \pm 2.09$ & $0.26 \pm 0.12$ & $-32.1 \pm 3.07$ & Generation of bubbles during sonication \\
$100 \mathrm{~W}, 240 \mathrm{~s}$ & $181.9 \pm 1.72$ & $0.31 \pm 0.07$ & $-31.7 \pm 1.82$ & Good transparence and dispersity \\
$200 \mathrm{~W}, 240 \mathrm{~s}$ & $164.2 \pm 1.80$ & $0.25 \pm 0.1$ & $-34.9 \pm 2.15$ & Good transparence and dispersity \\
\hline
\end{tabular}

Abbreviation: PDI, polydispersity index. 


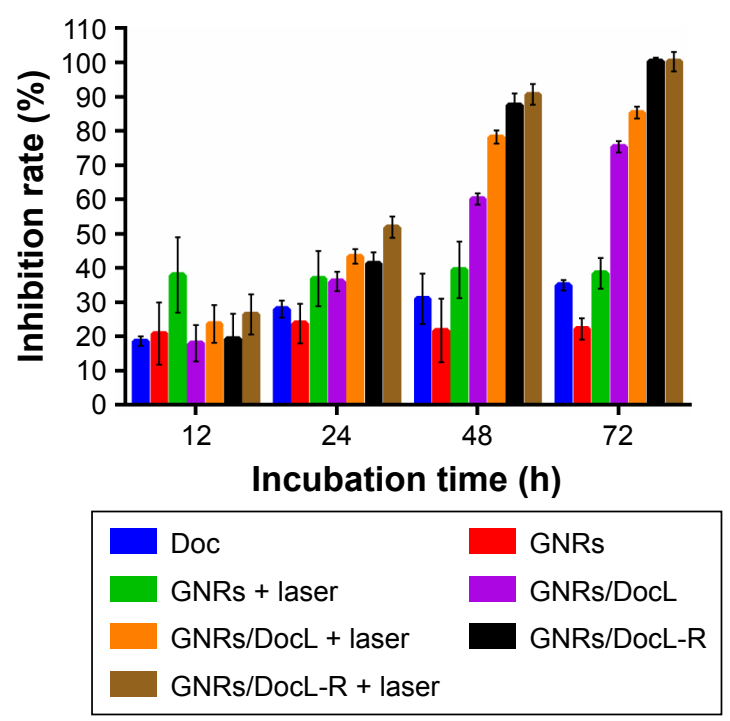

Figure SI PC-3 cell inhibition caused by the listed treatments.

Notes: Data are presented as mean \pm SD $(n=3)$. Concentration of Doc, $80 \mu g / m L$; concentration of GNRs, $0.023 n M$.

Abbreviations: Doc, docetaxel; GNRs, gold nanorods; GNRs/DocL-R, GNRs/Doc-liposome-RLT; PC-3, prostate cancer cell line.

$1 \mathrm{~h}$
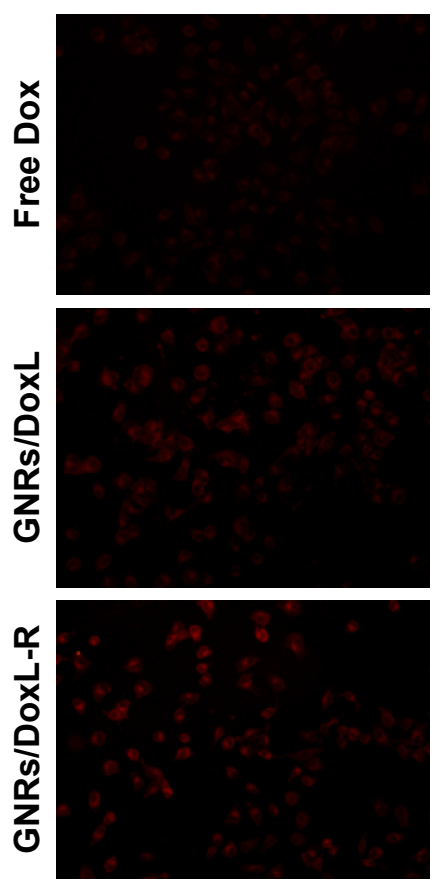

$2 \mathrm{~h}$
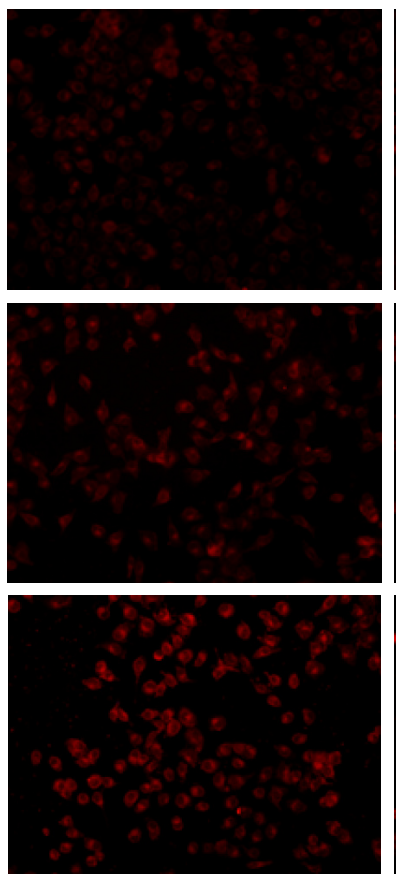

$3 \mathrm{~h}$
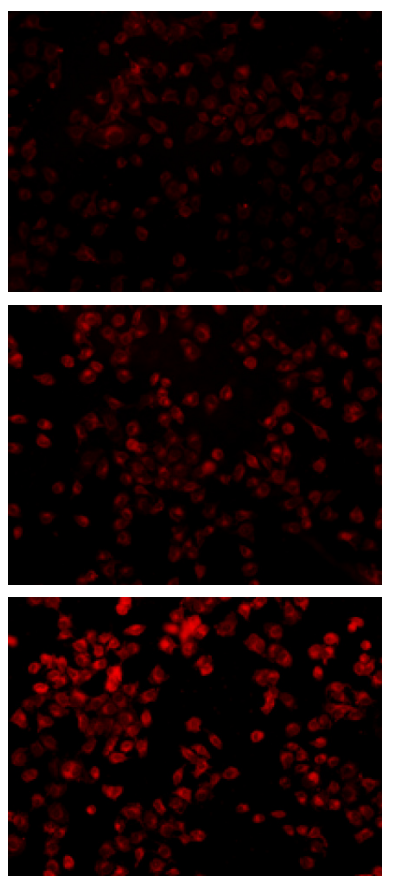

Figure S2 Cellular uptake of Dox by PC-3 cells.

Abbreviations: Dox, doxorubicin; PC-3, prostate cancer cell line.

International Journal of Nanomedicine

\section{Publish your work in this journal}

The International Journal of Nanomedicine is an international, peerreviewed journal focusing on the application of nanotechnology in diagnostics, therapeutics, and drug delivery systems throughout the biomedical field. This journal is indexed on PubMed Central, MedLine, CAS, SciSearch $₫$, Current Contents $® /$ Clinical Medicine,

\section{Dovepress}

Journal Citation Reports/Science Edition, EMBase, Scopus and the Elsevier Bibliographic databases. The manuscript management system is completely online and includes a very quick and fair peer-review system, which is all easy to use. Visit http://www.dovepress.com/ testimonials.php to read real quotes from published authors. 